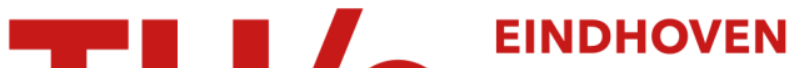 UNIVERSITY OF TECHNOLOGY
}

\section{High-strength/high-modulus structures based on flexible macromolecules : gel-spinning and related processes}

\section{Citation for published version (APA):}

Lemstra, P. J., Kirschbaum, R., Ohta, T., \& Yasuda, H. (1987). High-strength/high-modulus structures based on flexible macromolecules : gel-spinning and related processes. Developments in Oriented Polymers, 2, 39-77.

\section{Document status and date:}

Published: 01/01/1987

\section{Document Version:}

Publisher's PDF, also known as Version of Record (includes final page, issue and volume numbers)

\section{Please check the document version of this publication:}

- A submitted manuscript is the version of the article upon submission and before peer-review. There can be important differences between the submitted version and the official published version of record. People interested in the research are advised to contact the author for the final version of the publication, or visit the $\mathrm{DOI}$ to the publisher's website.

- The final author version and the galley proof are versions of the publication after peer review.

- The final published version features the final layout of the paper including the volume, issue and page numbers.

Link to publication

\section{General rights}

Copyright and moral rights for the publications made accessible in the public portal are retained by the authors and/or other copyright owners and it is a condition of accessing publications that users recognise and abide by the legal requirements associated with these rights.

- Users may download and print one copy of any publication from the public portal for the purpose of private study or research.

- You may not further distribute the material or use it for any profit-making activity or commercial gain

- You may freely distribute the URL identifying the publication in the public portal.

If the publication is distributed under the terms of Article 25fa of the Dutch Copyright Act, indicated by the "Taverne" license above, please follow below link for the End User Agreement:

www.tue.nl/taverne

Take down policy

If you believe that this document breaches copyright please contact us at:

openaccess@tue.nl

providing details and we will investigate your claim. 
66. Wilding, M. A. and Ward, I. M. (1978). Polymer, 19, 969.

67. Woods, D. W., Busfield, W. K. and WARD, I. M. (1985). Plast. Rubb. Process. Appln., 5, 157.

68. Robinson, I. M., Yeung, P. H. J., Galiotis, C., Young, R. J. and Batchelder, D. N. (1986). J. Mater. Sci., 21, 3440.

69. Dobi, M. G., Johnson, D. J. and Saville, B. P. (1981). Polymer, 22, 960.

70. KeLLER, A., personal communication.

71. Pietralla, M. (1976). Colloid Polym. Sci., 254, 249.

72. Bevis, M. (1978). Colloid Polym. Sci., 256, 234.

73. YounG, R. J. (1979). In: Developments in polymer fracture (Ed. E. H. Andrews), Applied Science Publishers, London.

74. BATCHELDER, D. N., personal communication.

75. Brenner, S. S. (1962). J. Appl. Phys., 33, 33.

76. KELly, A. (1966). Strong solids, Clarendon Press, Oxford.

77. MARSH, D. M. (1963). In: Fracture in solids (Ed. D. C. Drucker and J. J. Gilman), Interscience, New York.

78. Kinloch, A. J. and Young, R. J. (1983). Fracture behaviour of polymers, Applied Science Publishers, London.

79. KausCh, H. H. (1978). Polymer Fracture, Springer-Verlag, Berlin.

80. HuLl, D.(1981). An introduction to composite materials, Cambridge University Press.

81. Ladizesky, N. H. and WARD, I. M. (1985). Pure Appl Chem, 57, 1641.

82. Greenwood, J. H. and Rose, P. G. (1974). J. Mater. Sci., 9, 1809.

83. Galiotis, C., Yeung, P. H. J., Young, R. J. and Batchelder, D. N. (1984). J. Mater. Sci., 19, 3640.

84. Young, R. J., Galiotis, C., Robinson, I. M. and Batchelder, D. N. J. Mater. Sci. (Submitted for publication.)

85. Cox, H. L. (1952). Brit. J. Appl. Phys., 3, 72.

86. Batchelder, D. N. (1976). J. Polym. Sci. Polym. Phys. Ed., 14, 1235.

87. DeTeresa, S. J., Allen, S. R., Farris, R. J. and Porter, R. S. (1984). J. Mater. Sci., 19, 57.

88. Thomas, E. L. (1985). Polymer Prepr., 26, 314.

89. Galiotis, C., Robinson, I. M., Young, R. J., Smith, B. E. J. and Batchelder, D. N. (1985). Polymer Commun., 26, 354.

Chapter 2

\section{HIGH-STRENGTH/HIGH-MODULUS STRUCTURES BASED ON FLEXIBLE MACROMOLECULES: GEL- SPINNING AND RELATED PROCESSES}

\author{
P. J. LEMSTRA*, R. KiRSChBAUM
}

DSM, Central Research, Geleen, The Netherlands

T. OHTA and H. YASUdA

Toyobo, Katata Research Institute, Ohtsu, Shiga, Japan

\section{INTRODUCTION}

Amongst the various developments in the area of high-performance fibres, two major routes can be discerned which are completely different in respect of the starting (base) materials, respectively intrinsically rigid as opposed to intrinsically flexible macromolecules.

\subsection{Rigid Chains}

More than 50 years ago Carothers and $\mathrm{Hill}^{1}$ formulated the conditions requisite for the production of a 'useful fibre', such as the necessity for long chain molecules which are perfectly ordered in an array with the chain axis parallel to the fibre direction. Along these lines the design and development of intrinsically stiff macromolecules forms, at least in retrospect, a logical approach to the exploitation of the intrinsic possibilities with respect to stiffness and strength of a covalently bonded

* Present address: Department of Polymer Technology, Eindhoven University of Technology, Eindhoven, The Netherlands. 
array of atoms, since chain-extension and alignment are achieved comparatively easily (not taking into account the sophisticated chemical work done beforehand) in comparison with flexible macromolecules.

Examples of really rigid chain molecules are PBT (poly-p-phenylene benzobisthiazole) and its molecular analogue PBO (poly-p-phenylene benzobisoxazole). In both cases the persistence length, $P$, measured by light scattering in dilute solutions is, within experimental error, identical with the contour length, $L$, indicative of a 'rigid rod nature'. ${ }^{2}$ Typical tensile properties ${ }^{3}$ of heat-treated PBT fibres spun from solution are: tenacity $3.5 \mathrm{GPa}$, modulus $250 \mathrm{GPa}$ and elongation at break $1.2 \%$, or the specific values for strength and stiffness, viz. $2 \cdot 2 \mathrm{~N}$ tex $^{-1}$ (see Table 4 for conversion of units) and $160 \mathrm{Ntex}^{-1}$ respectively (density of PBT is $\sim 1.6 \mathrm{~g} \mathrm{~cm}^{-3}$ )

The prime examples of rigid chain polymers however are the aromatic polyamides (aramids), notably poly ( $p$-phenylene terephthalamide) (PPTA) marketed under the trade names of Kevlar (DuPont) and Twaron (Akzo/Enka). The tensile properties of e.g. the Kevlar 49 grade are: tenacity $3 \mathrm{GPa}$, modulus $130 \mathrm{GPa}$ and strain at break $2 \%$ or, in specific values, tenacity $2 \mathrm{~N}$ tex $^{-1}$ and modulus $90 \mathrm{~N}^{-1} \mathrm{x}^{-1}$ (the density of PPTA is $1.45 \mathrm{~g} \mathrm{~cm}^{-3}$ ).

Although the aromatic polyamides are not strictly rigid chains ${ }^{3,4}$ (for PPTA the ratio $L / P$ is about 4 ), experimental conditions have been found to promote chain-extension and orientation in the fibre direction. These experimental conditions encompass spinning from liquid crystalline (nematic) solutions and optimized spinning and coagulation procedures followed by heat treatment under tension to promote and retain a high degree of chain-orientation/extension in the fibre direction to achieve optimum mechanical properties. ${ }^{5}$

\subsection{Flexible Chains}

Flexible (regular) chains tend to fold during crystallization (see Section 1.3), and consequently in conventional spinning methods folded-chain type crystals will be formed during solidification (melt-spinning), solvent evaporation (dry-spinning) or coagulation (wet-spinning). Of course this statement is an oversimplification of reality since, during spinning of stereo-irregular polymers such as poly(acrylonitrile), L-L phase separation takes place during coagulation and chain-folding is not very pronounced. Nevertheless, the tendency to form folded-chain crystals shown by crystallizable polymers such as the polyamides, polyesters, polypropylene and polyvinylalcohol during solidification from the melt or
TABLE 1

ELASTIC MODULI: $:^{6,7}$ COMPARISON BETWEEN THEORETICAL AND ACTUAL VALUES

\begin{tabular}{lcc}
\hline & $E_{\text {actual }}(G P a)$ & $E_{\text {theor }}(G P a)$ \\
\hline Polyvinylalcohol & 30 & $200-250$ \\
Polyester (PETP) & 20 & $120-150$ \\
Polyamide (nylon-6) & 6 & $170-270$ \\
Polypropylene & 12 & $35-49$ \\
\hline
\end{tabular}

solution is hindering for achieving chain-extension and formation of hightenacity fibres by conventional spinning methods.

Transformation of the as-spun structures into chain-extended type crystals via well known post-drawing techniques, usually in a temperature range close to but below the melting point, is only partly successful, at least if we compare the values of axial (Young's) moduli of large-scale manufactured technical yarns with their theoretical limits (see Table 1).

The theoretical moduli and the actual values for technical yarns (Table 1) indicate a major gap between practical and theoretical limits. Comparison with the moduli of high-performance fibres based on rigid chains makes it clear that the conventional spinning techniques involving post-tensile drawing are highly inadequate for the production of highstrength/high-modulus structures based on flexible macromolecules. In Table 1 no reference is made to theoretical values for tenacity since this property, in contrast with low-strain properties such as moduli, is difficult to estimate for real (finite chain) systems (see below).

\subsection{Polyethylene vs. Other Polymers}

Soon after the discovery of linear polyethylene (Ziegler, 1954), an important feature was found: the phenomenon of folded-chain crystallization. Storks ${ }^{8}$ had mentioned the possibility of chain folding during crystallization, on the basis of electron diffraction studies of thin films of gutta-percha in 1938. The concept of chain folding, however, remained unnoticed until about 1955 , when polyethylene single crystals were obtained from dilute solutions. ${ }^{9}$ Keller concluded from the electron diffraction pattern of PE single crystals that the direction of the chains was perpendicular to the basal plane, as shown schematically in Fig. 1.

Although the concept of chain-folded crystallization of PE and other regular/flexible macromolecules has fascinated many scientists up to now, scattered research activities had already started in the 1960 s to pursue chain extension. Polyethylene featured as the prime candidate in these 

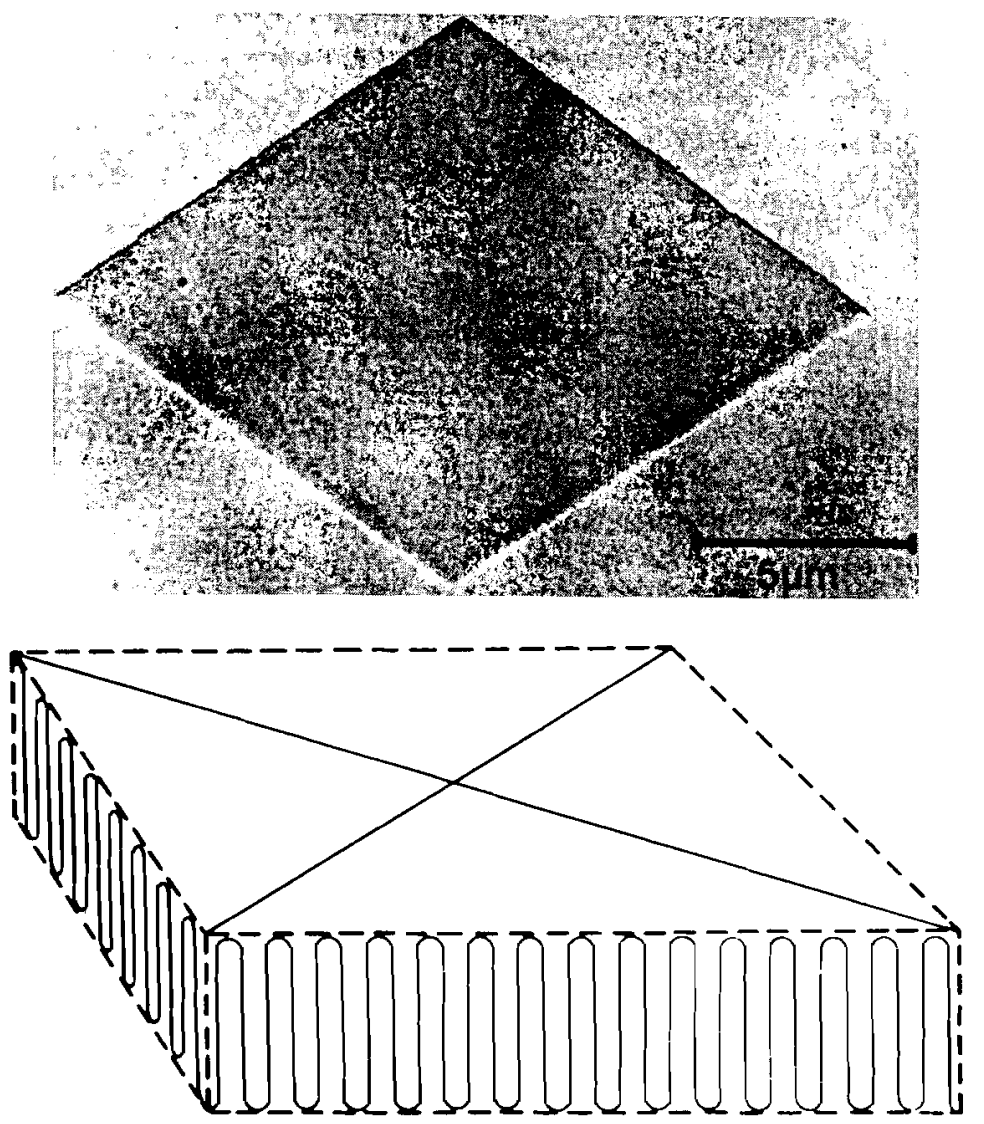

FIG. 1. Electron micrograph of PE single crystal and schematic representation of macromolecules within the crystal. (Courtesy of Prof. A. Keller, Bristol.)

studies, partly due to its simple chemical structure and its availability in a wide range of chain lengths, but also due to its intrinsic possibilities. Polyethylene can be synthesized with molecular weights exceeding $10^{6} \mathrm{~kg} \mathrm{kmol}^{-1}$ and with a nearly linear structure. The zig-zag chain conformation in the solid state and the absence of pendant groups implies that the PE chain has a small cross-sectional area and consequently that the number of load-bearing elements per fibre cross-section is high provided the chains are fully extended in the fibre direction. Theoretica calculations showed that the strength of linear PE could be as high as $19-25 \mathrm{GPa},{ }^{10,11}$ with a corresponding modulus of about $300 \mathrm{GPa}$. One
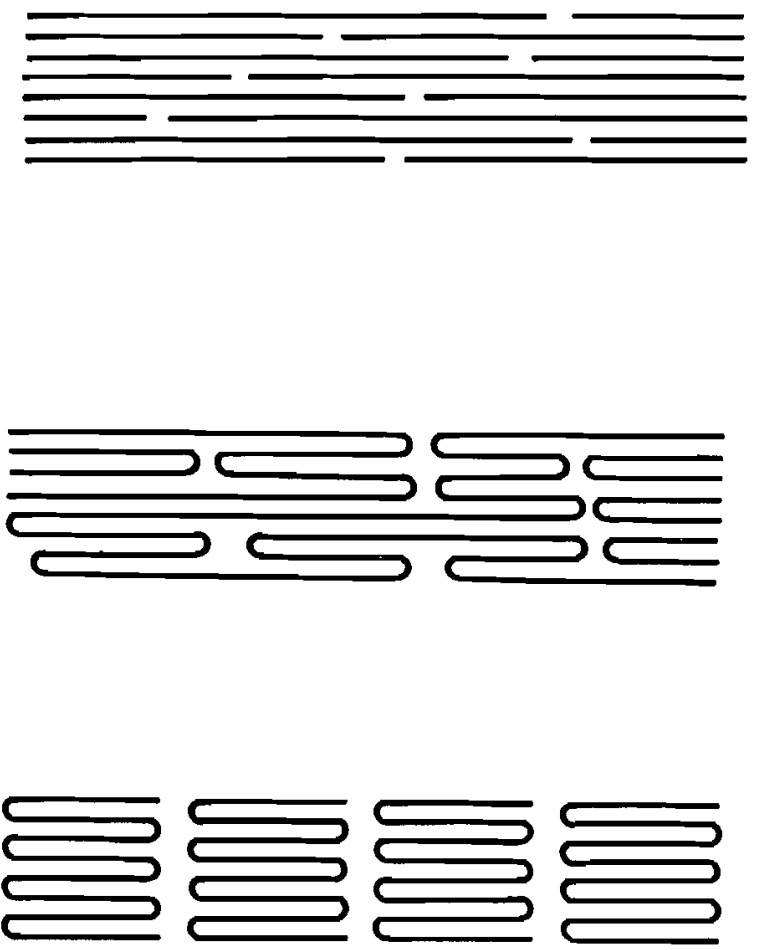

FIG. 2. Chain-orientation vs. chain-extension.

has to be cautious in using these strength values because they were calculated from loading individual and infinite chains to the limit (rupture of $\mathrm{C}-\mathrm{C}$ bonds). Actually, we have to deal with finite chains and the maximum tenacity values are determined by other factors such as chain length, degree of chain orientation, crystallinity and crystal size and, above all, chain extension and topology. This is shown schematically in Fig. 2 for three examples, all possessing nearly perfect chain orientation but having a very different degree of chain extension. It is clear without further comment that the tenacity increases from virtually zero to its maximum value.

\subsection{Aim (Scope) of Review}

The origin and development of various techniques and processes to produce high-strength/high-modulus PE structures will be reviewed, with emphasis on solution-spinning techniques in Section 2. The basic aspects 
TABLE 2

SOME HIGH-PERFORMANCE FIBRES COMPARED

\begin{tabular}{l} 
Material \\
$\begin{array}{c}\text { Specific } \\
\text { tenacity } \\
\left(N \text { tex }{ }^{-1}\right)\end{array}$ \\
$\begin{array}{c}\text { Specific } \\
\text { modulus } \\
\left(N \text { tex }^{-1}\right)\end{array}$ \\
\hline PE-PE (isotropic)
\end{tabular}

and proposed mechanisms for ultra-drawing of polyethylene will be discussed in Section 3. Properties of high-performance PE fibres will be presented in Section 4 and the recent results on other flexible polymers will be summarized in Section 5. The structure of oriented PE and modelling is not discussed. Many models for drawn polymers exist (see e.g. Reference 12), and the variety of models alone for drawn PE to describe its structure and properties is indicative of a lack of detailed information on a molecular level. Standard techniques such as X-ray scattering, birefringence etc. reveal chain orientation but fail to provide adequate information about chain extension.

The techniques and processes discussed certainly do not constitute a recipe for making high-strength/high-modulus structures from flexible polymers. On the contrary, polyethylene is rather an exception amongst its class of flexible chain molecules and currently pre-marketed highperformance PE fibres (HP-PE) are exceptional if we compare their specific tensile properties with those of other high-performance fibres, the more so if we take into account its simple chemical structure in relation to properties (see Table 2).

\section{HISTORICAL SURVEY}

Numerous publications exist on the drawing behaviour of polyethylene and the related crystal structure and morphology of oriented PE structures. It is impossible within the scope and purpose of this review to discuss and comment upon the various contributions in this field. Therefore a selection has been made of views, experimental results and techniques which are directly related to current processes for the production of high-strength/high-modulus PE fibres. It is, of course, in retrospect always possible to select those experimental results from the literature which, after being presented in chronological order, will give the impression that the development towards the production of highstrength/high-modulus PE fibres has been straightforward. This is however far from reality; in fact the route towards current processes has been a tortuous one and, as usual, serendipity has played an important role, as can be inferred from the literature survey presented below.

\subsection{Early Attempts (before 1970)}

\subsubsection{Solution Routes}

Solution-spinning of linear polyethylene dates back to 1956, when a patent application was filed by the Vereinigte Glanzstoff-Fabriken (now Akzo-Enka) concerning wet-spinning of polyolefins. ${ }^{13}$ The inventor, Jurgenleit, reported spinning of linear polyethylenes from moderately concentrated solutions, 10-18\%; after post-drawing the spun filaments, tenacities up to $1.2 \mathrm{GPa}$ were obtained. Similar values for tenacity were found by Sato and Hirai in spinning concentrated PE solutions and subsequent drawing. ${ }^{14}$

Solution-spinning of ultra-high molecular weight (UHMW) PE $\left(M_{\mathrm{w}}>\right.$ $\left.10^{6} \mathrm{~kg} \mathrm{kmol}^{-1}\right)$ was performed by $\mathrm{Zwick}^{15}$ from naphthalene solutions. No post-drawing was mentioned in his patent application, nor were fibre properties discussed. Blades and White ${ }^{16}$ introduced their so-called flashspinning technique. A pressurized solution of linear polyethylene (meltindex 0.5 and solution concentration $13 \%$ in halogenated hydrocarbons) was extruded at high speeds and temperatures (about $200^{\circ} \mathrm{C}$ ). The fibrillated strand yarn which precipitated upon rapid cooling and almost instantaneous solvent evaporation was subjected to slow drawing. Maximum values for tenacity and modulus were reported to be about $1.4 \mathrm{GPa}$ and $20 \mathrm{GPa}$, respectively.

\subsubsection{Chain Extension in Solution}

Mitsuhashi ${ }^{17}$ was probably the first to attempt inducing chain extension directly in solution. Figure 3 shows his original drawing of a Couette type apparatus used in the early 1960s. Mitsuhashi reported the formation of fibrous 'string-like' PE structures upon stirring of linear polyethylene 
(Marlex 50) in xylene. No mechanical properties of the fibrous crystal mats precipitated on the rotor surface were reported. His original observations remained practically unnoticed until about 10 years later a similar experimental set-up was used by Pennings et al. (see below) and the 'stringlike' PE structures were baptized 'shish-kebab' structures.

Stirring polymer solutions to induce chain extension is less obvious than might be thought at first sight. In general, to stretch the chain the hydrodynamic driving force should exceed the entropic restoring force towards the random coil conformation. The type of flow is important and elongational flows are particularly suitable in view of the aim of fully stretching out an individual macromolecule. ${ }^{18}$ The following conditions are claimed to hold for chain extension: ${ }^{19}$

$$
\dot{\varepsilon} . \tau>1 ; \quad \dot{\varepsilon} . \Delta t>1
$$

In eqn (1), $\dot{\varepsilon}$ is the strain rate, $\tau$ the characteristic relaxation time and $\Delta t$ the time during which the macromolecule is exposed to the flow field. The relaxation time is strongly dependent on molecular weight.

Mackley and Keller ${ }^{20}$ estimated for polyethylene in dilute solutions that $\tau \approx M^{1.75}$, and recent studies ${ }^{21}$ for monodisperse polystyrene gave $\tau \approx M^{1 \cdot 5}$. In dilute solutions at polymer concentrations $\phi \geq \phi^{*}\left(\phi^{*}\right.$ is the overlap concentration), and in good solvent systems, only fractional chain extension will be obtained in the case of linear polyethylene due to the broad molecular weight distribution. It was calculated ${ }^{20}$ for the system polyethylene in xylene that at a strain rate of $1000 \mathrm{~s}^{-1}$ only molecules with molar masses $>2 \times 10^{6}$ will become fully stretched out. The extremely high strain rates require special devices for chain extension. ${ }^{21}$

The observation of Mitsuhashi that in a simple Couette type apparatus oriented PE structures could be produced is, in retrospect, due to two main factors. In semi-dilute solutions (in the case of Mitsuhashi $\phi>2 \%$ ) entanglement-coupling plays an important role and induced chain extension can be made permanent if the solution is slightly supercooled by nucleation and alignment of (partly) oriented chains (to be discussed below).

\subsubsection{Single Crystal Drawing}

Fundamental drawing studies, involving PE single crystals, were undertaken by Statton ${ }^{22}$ and Maeda et al. ${ }^{23,24}$ It was reported that single crystal mats of $\mathrm{PE}$ were remarkably ductile at elevated temperatures, $100-120^{\circ} \mathrm{C}$, i.e. close to but below the melting point. Later studies by Barham and Keller ${ }^{25}$ showed that PE single crystal mats could be drawn up to $40 \times$ with corresponding moduli of about $50 \mathrm{GPa}$. The main

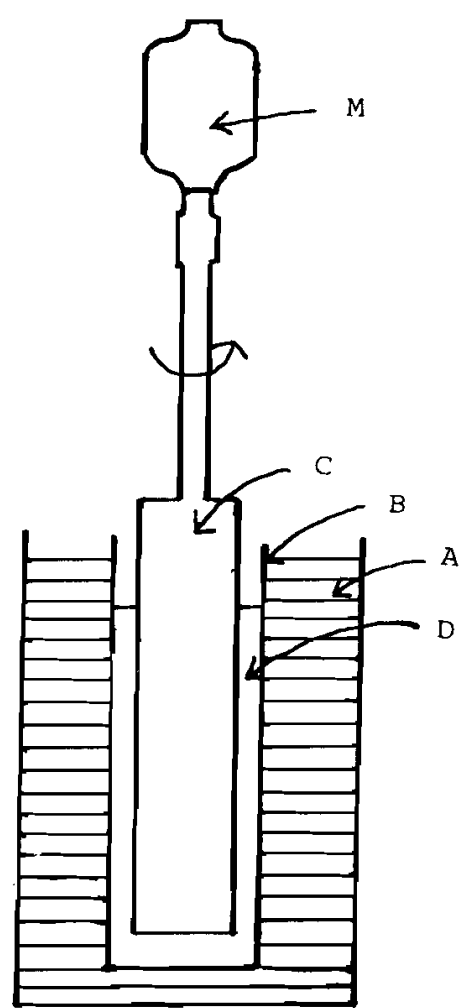

FIG. 3. Stirring-induced crystallization: $\mathbf{M}$, motor; A, oil thermostat; B, cylinder containing PE solution (D); C, rotor. (From original photograph by S. Mitsuhashi.)

conclusion from Statton's original work is that folded-chain crystals grown from dilute solutions are ductile at elevated temperatures and unfold rather easily in the direction of the applied stress, an observation which was comprehended more than ten years later to its full extent after the invention of the gel-spinning process.

\subsection{Developments during 1970-80}

\subsubsection{Deformation in the Solid State}

In 1970 Andrews and Ward ${ }^{26}$ started systematic drawing studies of spun/melt crystallized PE filaments. They reported that the axial Young's modulus of the drawn filaments increased with increasing draw ratio and moduli of up to about $20 \mathrm{GPa}$. Later, Ward et $a l^{27}$ studied the influence of 


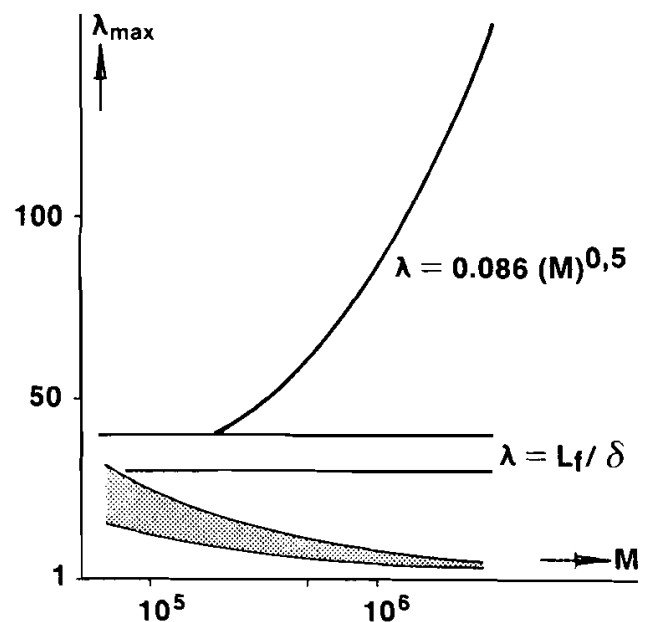

FIG. 4. Maximum extensibility of PE macromolecules and maximum observed draw ratio of melt-crystallized PE in the solid state (shaded area) as a function of molecular weight, $M$

spinning and quenching/cooling conditions of the as-spun filaments on the maximum drawability. Via optimization of the spinning and solidification conditions, fibres could be obtained possessing moduli of up to about $70 \mathrm{GPa}$, or specific values exceeding the stiffness of glass and steel. Meltspinning followed by ultra-drawing in a temperature range close to but below the melting temperature is however limited to certain molecular ranges, for two reasons:

(a) With increasing molecular weight, melt-spinning becomes increasingly difficult due to a strong rise in melt viscosity, and related phenomena such as melt fracture are prohibitive to continuous in-line spinning/drawing. An upper limit is an $M_{w}$ of about $5 \times 10^{5}$.

(b) With increasing molecular weight, melt-crystallized polyethylene increasingly resists deformation in the (semi-)solid state, i.e. postdrawing of melt-spun filaments becomes less adequate. The decrease in drawability/draw ratio with increasing molecular weight was studied systematically by Ward and coworkers and Fig. 4 shows their experimental results for the maximum draw ratio as a function of molecular weight of melt-crystallized polyethylenes (shaded area in Fig. 4). A limiting value for $\lambda_{\max }$ is obtained below 10 , for $M_{\mathrm{w}} \geq 10^{6} \mathrm{~kg} \mathrm{kmol}^{-1}$, sometimes referred to as a natural draw ratio.

The concept of a natural draw ratio has been established in tensile drawing of melt-spun filaments, for instance polyamides with $\lambda_{\max } \sim 56$. However, a limiting natural draw ratio is not predicted by any current model of polymer crystalline structure/morphology. The maximum extension ratio of chain molecules, which equals the extended chain length, $L$, divided by the end-to-end distance, can be estimated provided that the chain conformation is known. In the case of melt-crystallized polymers, the topology of chains is still very much a matter of debate. Although detailed studies on the drawing behaviour of polyethylene as a function of molecular weight, crystallization conditions etc. could provide interesting additional information with respect to the organization of chains in the solid state, we will simplify the actual complex situation by stating that in the case of melt-crystallized PE the chain conformation should lie between the two extremes (a) regularly folded (adjacent re-entry) and (b) random coils (Erstarrungsmodell ${ }^{28}$ ). In the case of regularly folded chain crystals the maximum molecular extension ratio is given by the ratio of the fold length, $L_{\mathrm{f}}$, and the chain diameter, $\delta$ :

$$
\lambda=L_{\mathrm{f}} / \delta
$$

and for random coils: ${ }^{29}$

$$
\lambda=0 \cdot 086(M)^{0 \cdot 5}
$$

As can be inferred from Fig. 4, the maximum molecular extension ratios are much higher than the maximum observed macroscopic draw ratios (shaded area). In the drawing of solid (flexible) polymers the macroscopic deformation correlates with the molecular extension, ${ }^{30}$ and it is clear from the calculated extension ratios that the decrease in drawability with $M$ for polyethylene is not related to the individual chains but to other factors, which will be discussed in Section 3.

Despite its limitations with respect to molecular weight, reflected in the ultimate strength values of about $1 \mathrm{GPa}$, melt-spinning/drawing of linear $\mathrm{PE}$ has advantages, such as its simplicity and consequently low cost price of the fibres and tapes, and, in terms of price performance, is attractive for many applications. ${ }^{31}$

Deformation in the solid state is not restricted to tensile drawing of spun filaments. Solid-state extrusion (hydrostatic extrusion) of pre-formed PE billets has been performed. ${ }^{32,33}$ In such processes one avoids the meltextrusion/spinning step but, as is clear from the discussion above, in 
deforming solid PE the same limitations are encountered with respect to molecular weight. In order to obtain high-modulus structures, high EDR's (extrusion draw ratios) are necessary, comparable to draw ratios in tensile drawing. More recently, the method of drawing through suitably profiled dies (die-drawing) has been reported as a means of producing three-dimensional oriented structures such as tubes and sheets. ${ }^{34}$

\subsubsection{Solution Routes}

In the mid-1960s it was found at DSM Central Research that fibrous PE crystals are formed in a Couette apparatus if the inner rotor exceeds a
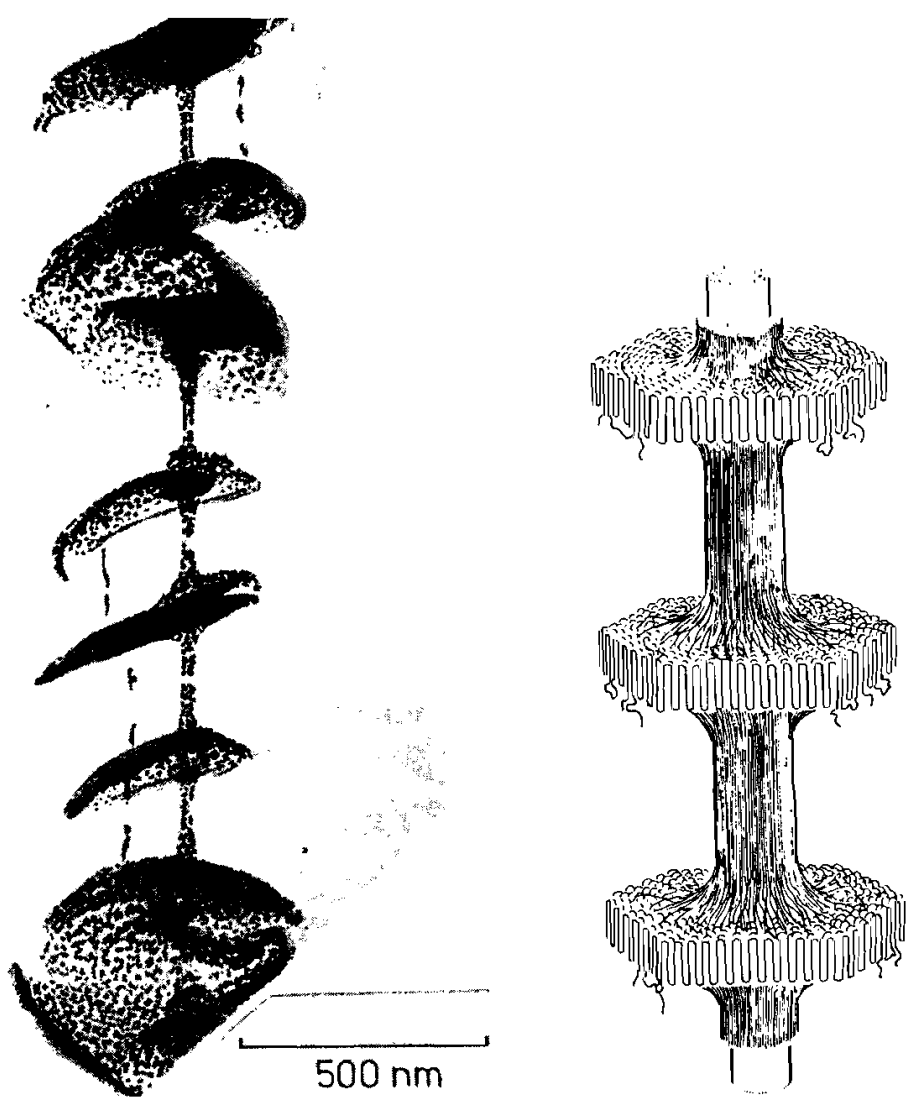

Fig. 5. Electron micrograph of PE 'shish-kebab' and schematic representation of macromolecular organization. (Courtesy of Dr M. Hill, Bristol.) critical rotation rate coinciding with the onset of Taylor vortices. ${ }^{35}$ The correlation between the onset of Taylor vortices, which are known to contain elongational components, and the formation of fibrous crystals became less pronounced when high molecular weight PE was employed. As mentioned before in discussing Mitsuhashi's work, formation of fibrous crystal structures in stirring semi-dilute, high molecular weight PE solutions is in part due to entanglement coupling, as became clear later after detailed studies on surface growth and gel-spinning (see below).

The morphology of stirring-induced fibres has become known as the 'shish-kebab', a central core consisting of more or less extended PE molecules (shish) and folded-chain type crystals deposited on the core (kebabs); see Fig. 5. For a detailed discussion of the formation of shishkebabs the reader is referred elsewhere. ${ }^{19,36,37}$

The structure of shish-kebab type fibrous polyethylene is far from the ideal arrangement of PE macromolecules with respect to stiffness and strength, and reflects once more the problem of obtaining full chainextension. Due to the presence of lamellar overgrowth, moduli of precipitated fibrous PE 'shish-kebabs' were limited to up to about $25 \mathrm{GPa},{ }^{38}$ to be compared with $>50 \mathrm{GPa}$ in the cases of meltspinning/drawing and single-crystal drawing.

The work on stirring-induced crystallization was followed by various techniques such as free growth, ${ }^{39}$ culminating in the so-called surfacegrowth technique. ${ }^{40}$ Figure 6 shows a schematic representation of this technique. A seed fibre is immersed in a dilute solution of UHMW-PE and from the surface of the rotating inner-cylinder fibrous, tape-like polyethylene structures can be withdrawn. Under optimized experimental

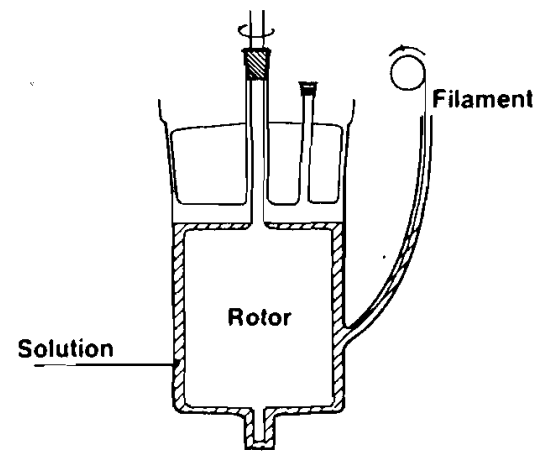

Fig. 6. Schematic representation of surface-growth technique. (Taken from Reference 40.) 


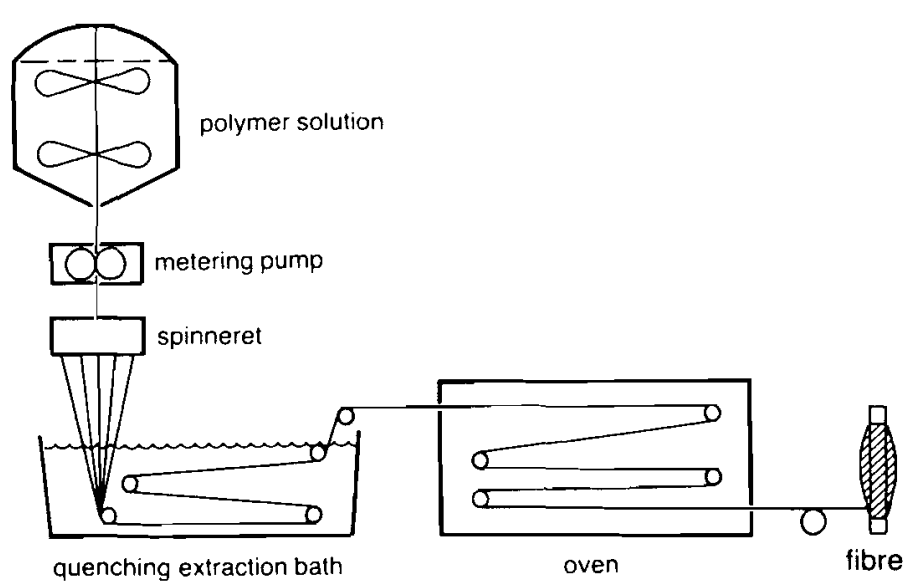

FIG. 7. Schematic representation of gel-spinning process.

conditions with respect to solution concentration, temperature and takeup speed, oriented PE structures could be obtained possessing tensile moduli of over $100 \mathrm{GPa}$ and strength values above $3 \mathrm{GPa}$. This technique was studied in detail by Zwijnenburg, Meihuizen, and Pennings (University of Groningen) ${ }^{41}$ and by Barham and Keller (University of Bristol), ${ }^{37}$ and in fact represents a milestone since it provided the experimental proof that high-modulus/high-strength PE structures based on UHMW-PE were possible. Although a lot of effort was devoted to understand the paramount factors governing the speed and production of oriented PE in the surface-growth technique, a technological process was not feasible in view of the limited take-up speeds, which were lower than $1 \mathrm{~m} \mathrm{~min}^{-1}$.

At the end of the 1970s a remarkable observation was made at DSM Central Research. It was found that solution-spun UHMW-PE filaments could be ultra-drawn to high-strength/high-modulus fibres, with tenacity $>3 \mathrm{GPa}$ and corresponding Young's moduli of over $100 \mathrm{GPa}{ }^{42}$ Figure 7 shows schematically this process, now often referred to as gel-spinning. A solution of UHMW-PE is spun into a bath, for instance water, and upon cooling solidification/crystallization takes place producing a gel-like appearance due to immiscibility of the solvent with water. The asspun/quenched filaments are mechanically sufficiently stable to be transported via a roller system into an oven in which super-drawing is performed at elevated temperatures. At first glance, gel-spinning seems identical with standard solution-spinning. The remarkable feature,

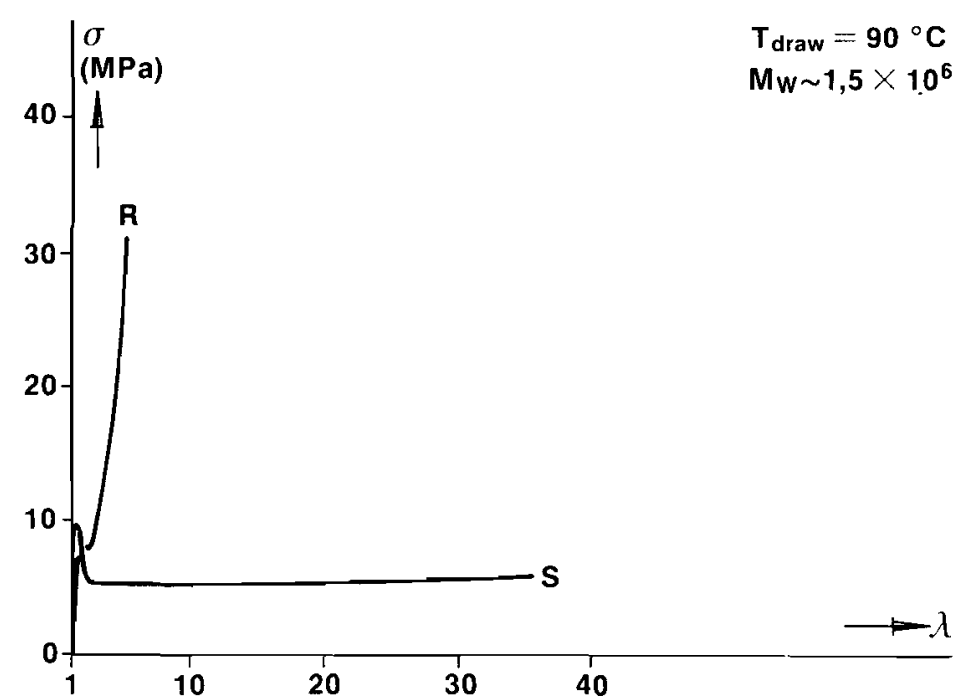

FIG. 8. Stress-strain behaviour (nominal stress) of respectively melt-crystallized (R) and solution-crystallized (S) UHMW-PE; the solution-cast film (initial polymer conc. $2 \%$ ) was dried and extracted.

however, is that even after complete solvent removal from the as-spun filament, for instance by extraction, ultra-drawing is still possible. Figure 8 demonstrates the difference in drawability between melt-crystallized and solution-spun/cast UHMW-PE in the solid state, and Fig. 9 shows the effectiveness of the tensile drawing procedure. Figure 9 presents the data from the original patent applications ${ }^{42}$ based on isothermal drawing, but
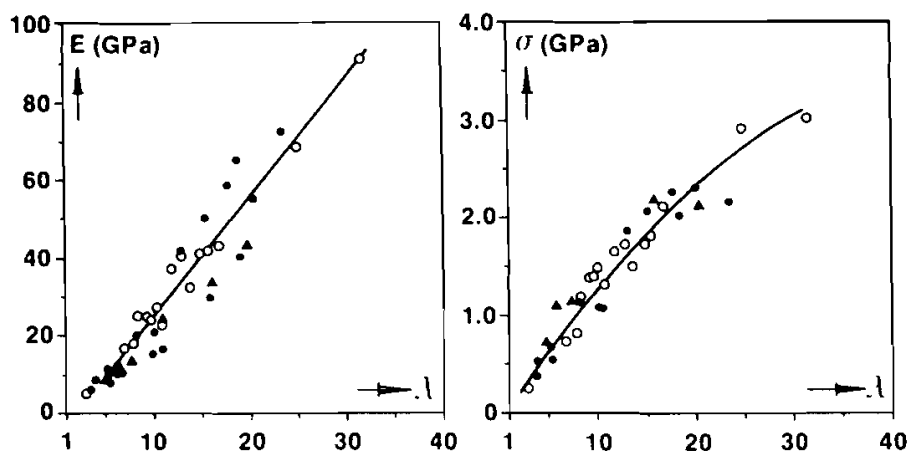

FIG. 9. Effectiveness of drawing gel-filaments: $\bigcirc$, 'wet' filaments $(90 \%$ residua solvent); $\boldsymbol{O}$, partly dried filaments $(6 \%$ residual solvent); $\boldsymbol{\Delta}$, dried (extracted) filaments; drawing performed single-stage at $120^{\circ} \mathrm{C}$. 
through optimization of the drawing procedure, such as multi-stage drawing, tenacities of between 3 and $4 \mathrm{GPa}$ and moduli of up to $150 \mathrm{GPa}$ can be realized by in-line spinning/drawing; see Section 4 .

The striking observation is that HMW-PE, $M_{\mathrm{w}}>5 \times 10^{5}$, can be ultradrawn after spinning from solution, even after complete solvent removal from the as-spun filaments. In this respect there is a sharp contrast with melt-crystallized HMW-PE's (see Fig. 4). The major conclusion is that the 'constraints' which limit the drawability in melt-crystallized PE are removed by spinning/casting from solution.

\subsection{Recent Developments (since 1980)}

Since the invention of the gel-spinning process, several (patent) applications have appeared describing variations of this process, but the basic principles have not been challenged, as will be discussed in Section 3 .

Spinning of UHMW-PE solutions into extracting solvents was claimed to be essential for ultra-drawing of the as-spun filaments, due to induced porosity promoting drawability. In a recent review on advances in highstrength fibres ${ }^{43}$ it is stated that non-porous fibres in fact cannot be drawn to high draw ratios. In their patent applications, Kavesh and Prevorsek ${ }^{44}$ describe the spinning of UHMW-PE solutions and extraction of the solvent from the as-spun filaments with, in their terminology, a volatile solvent, leading to formation of a porous so-called 'xero-gel' fibre. These 'xero-gel' fibres are drawn in a two-stage process and mechanical properties are attained which are similar in magnitude to those obtained in 'standard' gel-spinning. The concept of porosity influencing the drawability was also discussed by Kalb and Pennings. ${ }^{45}$ The drawability of as-spun fibres is related to the mobility of the macromolecules, which is determined by various parameters as expressed by the simplified equation for non-recoverable creep: ${ }^{46}$

$$
\dot{\varepsilon}=A \exp [-(\Delta E-\sigma \Delta V) / k T]
$$

In eqn (4), $\dot{\varepsilon}$ is the creep rate, $\Delta E$ the activation energy for transport, $\sigma$ the applied stress and $\Delta V$ the activation volume. According to Kalb and Pennings an increase in free volume, the microporosity in the fibre to be drawn, will lead to improved drawability. The concept of porosity in relation to drawability will be discussed in Section 3.

A seemingly new method was introduced by Mitsui, the so-called meltkneeding process ${ }^{47} \mathrm{~A}$ mixture of UHMW-PE and paraffin wax (melting point between 40 and $120^{\circ} \mathrm{C}$ ) was extruded/spun, and after quenching in water the as-spun/quenched filaments or tapes were drawn in, for instance, $\mathrm{n}$-decane at $130^{\circ} \mathrm{C}$. Tenacities of the drawn fibres and tapes of up to $2.4 \mathrm{GPa}$ were reported and Young's moduli of up to $106 \mathrm{GPa}$.

On the more academic side, Statton's original work was resumed with the difference that now UHMW-PE single crystals were employed. Kanamoto et $a l .{ }^{48}$ prepared single crystal mats of UHMW-PE which were extruded in the solid state at low EDR values, 6-25 $\times$, and drawn subsequently. Tensile moduli of up to $220 \mathrm{GPa}$ were found at a corresponding draw ratio of about $250 \times$. From the various studies on the drawing of single crystal mats from UHMW-PE, ${ }^{49-51}$ the following main conclusions can be inferred:

(a) Single crystal mats based on UHMW-PE are extremely ductile in a temperature range close to but below the melting temperature, as demonstrated by maximum draw ratios in the range $200-400 \times$. However, the experimental observation that PE single crystals unfold quite easily in the direction of the applied stress at elevated temperatures had been found before by Statton. ${ }^{22}$

(b) In the case of UHMW-PE single crystal mats, the combination of high molecular weight and high achievable draw ratios results in nearly perfect chain-extended polyethylene structures, as reflected by various measured properties compared to theoretical values for perfect crystals (see Table 3).

The use of UHMW-PE single crystals is of less practical interest in view of the low polymer concentrations in solutions which are a prerequisite for growing single crystals, typically below $0.05 \%$, although the short-term mechanical properties obtained after super-drawing are superior. Apart from the impractical low solution concentrations, processing of precipitated single crystals by continuous extrusion is a slow and tedious

TABLE 3

COMPARISON OF VARIOUS (MAXIMUM) PROPERTIES MEASURED ON ULTRA-DRAWN UHMW-PE SINGLE CRYSTALS IN COMPARISON WITH THEORETICAL VALUES

\begin{tabular}{lcc}
\cline { 3 - 3 } \multicolumn{1}{c}{ Property } & Experimental & Theoretical \\
\hline Modulus $(\mathrm{GPa})$ & 220 & 250 (Ref. 7) \\
Density $\left(\mathrm{kg} \mathrm{m}^{-3}\right)$ & 990 & 1000 \\
Heat of fusion $\left(\mathrm{cal} \mathrm{g}{ }^{-1}\right)$ & $66 \cdot 9$ & 70 \\
Thermal expansion coefficient $\left({ }^{\circ} \mathrm{C}\right)^{-1}$ & $-1 \cdot 16 \times 10^{-5}$ & $-1 \cdot 18 \times 10^{-5}$ \\
\hline
\end{tabular}


process since the temperature should be kept strictly below the melting point to avoid a dramatic loss in drawability of the extrudate upon melting and recrystallization; see Section 3.

These disadvantages on the points of extrusion and low solution concentrations were eliminated by the so-called 'gel-press-method'.52 A semi-dilute solution of UHMW-PE was cooled and the resulting gel was pulverized to gel particles of about $80 \mu \mathrm{m}$. The gel particles were accumulated, compressed into sheets to be able to remove most of the solvent, and subsequently shaped via a heated die and post-drawn. During the die-drawing procedure, the solvent acts as a plasticizer and evaporates during post-drawing. The advantage of this process is that large diameter monofilaments or tapes can be produced based on UHMW-PE with tenacities above $2 \mathrm{GPa}$ and corresponding moduli of up to $130 \mathrm{GPa}$.

A new approach which does away with the necessity of using a solvent to produce ultra-drawable precursors, such as single crystals mats or asspun gel-filaments, was announced by Smith et al. ${ }^{53}$ using so-called 'virgin' disentangled PE. With the use of special polymerization conditions, UHMW-PE films were produced showing ultra-draw characteristics. The as-polymerized films were drawn at $135^{\circ} \mathrm{C}$ to produce oriented structures possessing a tenacity of $3.5 \mathrm{GPa}$ and corresponding moduli of $110 \mathrm{GPa}$.

\section{BASIC ASPECTS}

\subsection{Mechanism for Ultra-drawing}

At first sight it seems impossible to indicate a common mechanism for the various techniques and processes that have been developed for the production of high-modulus/high-strength polyethylene structures. However, confining considerations to the molecular scale, the prime observation has been that solution-spun/cast UHMW-PE, even after complete removal of solvent, is ultra-drawable as compared with meltcrystallized samples of identical chemical composition. This is, in fact, the essence of the invention of the gel-spinning process, ${ }^{42}$ the constraints which limit the drawability of melt-crystallized UHMW-PE (see Fig. 4, Section 2) are removed by spinning/casting from semi-dilute solutions. The role of the solvent is to induce a favourable structure for ultradrawing but once this structure is formed the solvent can be removed provided that the precursor thus generated is not destroyed by (partial) melting or dissolution (see below). From the influence of the initial polymer concentration in solution on the observed maximum drawability, it was concluded that the strongly enhanced drawability upon spinning/casting from solution is due to a reduction of the entanglementdensity in the gels or solid structures generated. ${ }^{54}$ In dissolving UHMW$\mathrm{PE}$, the number of contacts between chains decreases proportionally to the degree of dilution, i.e. disentangling of chains. In the limiting case of dilute solutions $\left(\phi<\phi^{*}\right)$, chains are separated and, upon cooling, individual folded-chain crystals will precipitate. Spinning or casting from solutions will yield folded-chain crystals during the quenching/solidification step as well, but a certain number of entanglements present in solution will be trapped in the gel or solid structure generated. Due to this trapping of entanglements coherent, gel-like (gel-spinning) filaments will be obtained upon spinning/quenching. In the case of hypothetical melt-spinning of UHMW-PE the situation in the melt (high entanglement density) is retained to a large extent in the solidified/quenched filaments. In the proposed model for the drawability of polyethylene in relation to solution concentration and crystallization history, it is assumed that the trapped entanglements act as physical cross-links that are semi-permanent on the time scale of the drawing experiment. In the case of melt-crystallized UHMW-PE the high entanglement density per chain is prohibitive to ultra-drawing whereas spinning/casting provides an optimum with respect to the entanglement density and coherence between the individual crystals to make in-line spinning/drawing feasible on a technological scale. Figure 10 shows the various possibilities with respect to the chain topology, taken from Reference 29. In Fig. 10 trapped entanglements are visualized as topologically interlocked loops. It should be noted that this model is a simplification of reality since the nature of entanglements is an experimentally elusive subject in macromolecular physics. ${ }^{21}$ However, the fact is that the discovery of gel-spinning and its explanation in terms of removal of 'molecular constraints', interpreted as entanglements, through dissolution prior to drawing has proved to be a viable concept which has not been challenged up to now. Studies on ultra-drawing of single crystals based on UHMW-PE ${ }^{4-50}$ demonstrate that, in the case of complete chain-disentangling through dilute solution, extremely high draw ratios can be obtained in the solid state in a temperature range close to but below the melting point, resulting in nearly perfect chain-extended PE structures.

Without specifying the nature and role of entanglements in the drawing process, it can be stated as a fact that chains are mutually uncrossable and that, to reach a situation in which chains are aligned parallel, the longchain molecules of UHMW-PE have to be disentangled prior to tensile drawing. The formation of folded-chain type crystals as an intermediate 

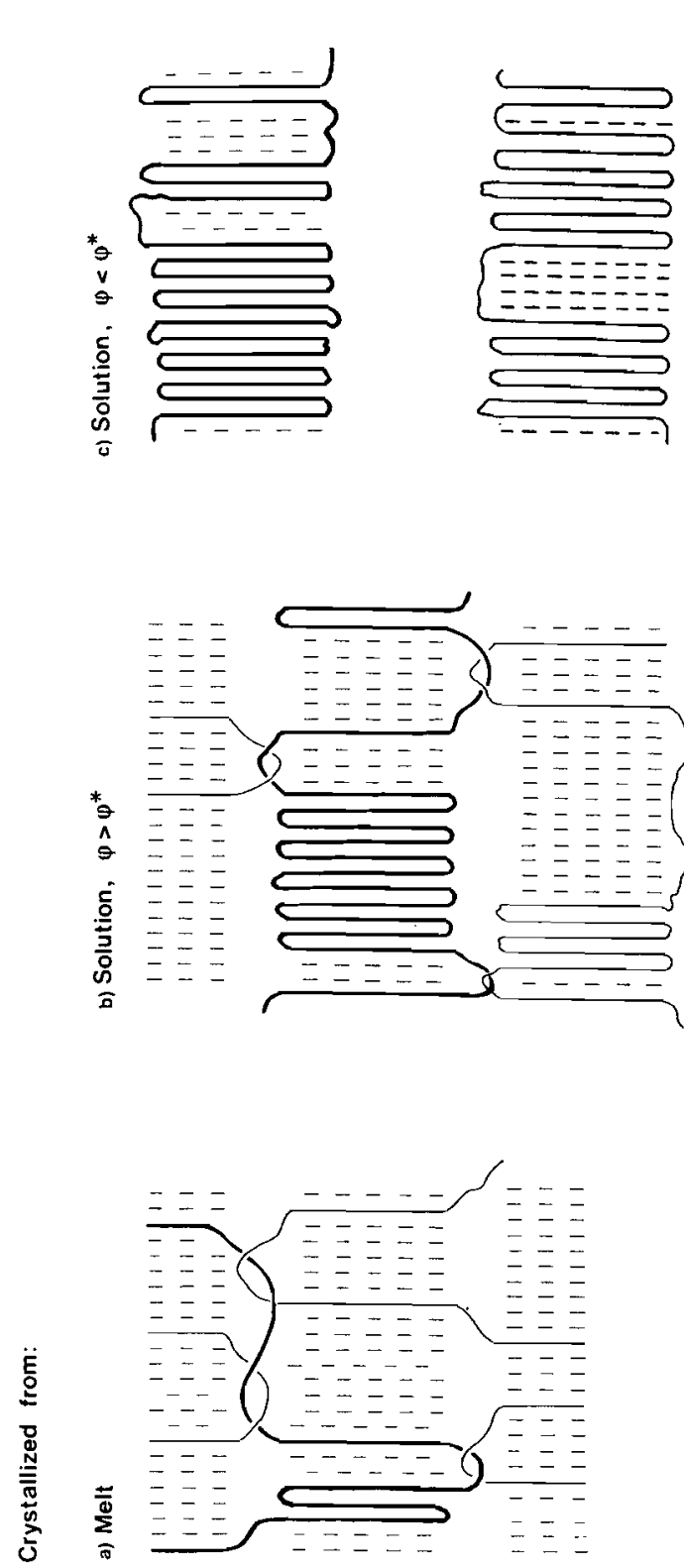

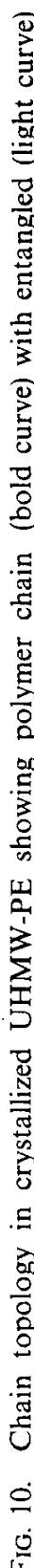

stage does not present a problem in the case of polyethylene since these crystals are ductile and unfold in the direction of the applied stress.

\subsection{Analysis of Other Techniques/Processes}

As mentioned in Section 2, porosity has been claimed to be important in ultra-drawing of UHMW-PE, on the basis of free-volume considerations. However, one should not confuse intermolecular (microscopic) free volume with intercrystalline (macroscopic) voids as induced by extraction of solvent from spun/cast filaments or films. ${ }^{55}$ This is demonstrated convincingly by the studies on drawing of UHMW-PE single crystals. Compression at room temperature to promote toughness in UHMW-PE single crystal mats ${ }^{56}$ or even solid-state extrusion at high pressure does not affect the ultra-draw characteristics, despite the fact that 'porosity' has been removed almost completely.

Melt-kneading of UHMW-PE and paraffin wax is a seemingly different process involving two solid constituents, at least at room temperature. The extrusion/spinning of this mixture is performed at temperatures between 180 and $300^{\circ} \mathrm{C}$. For the system UHMW-PE/paraffin wax, the thermodynamic behaviour can be calculated straightforwardly. The equilibrium melting (dissolution) temperatures are derived from the well known Flory melting-point depression relationship: ${ }^{57}$

$$
\frac{1}{T_{\mathrm{m}}}-\frac{1}{T_{\mathrm{m}}^{\circ}}=\left(\frac{R}{\Delta H_{\mathrm{u}}}\right)\left(\frac{V_{\mathrm{u}}}{V_{1}}\right)\left[(1-\phi)-\chi(1-\phi)^{2}\right]
$$

In eqn (5), $T_{\mathrm{m}}$ and $T_{\mathrm{m}}^{\circ}$ are the dissolution and the melting temperature of PE, $\Delta H_{\mathrm{u}}$ is the heat of fusion per repeating unit, $V_{\mathrm{u}} / V_{1}$ the molar volume ratio and $\phi$ the polymer volume fraction. Figure 11 shows the calculated dissolution temperatures for two molecular weights of paraffin and two values of the interaction parameter $\chi$. As is clear from Fig. 11, the actual extrusion temperature $\left(>180^{\circ} \mathrm{C}\right)$ used in the melt-kneading process is far above the dissolution temperature, and consequently the paraffin/ UHMW-PE system is a true solution during spinning/extrusion. Consequently melt-kneading is identical with solution-spinning/gel-spinning employing volatile solvents.

All processes discussed up to now involve a dissolution stage to disentangle the long-chain PE molecules either partly, to create a loose entanglement network structure as the ideal precursor for ultra-drawing (gel-spinning), or completely, i.e. production of UHMW-PE single crystals. In retrospect this concept has been used to explain the phenomenon of 


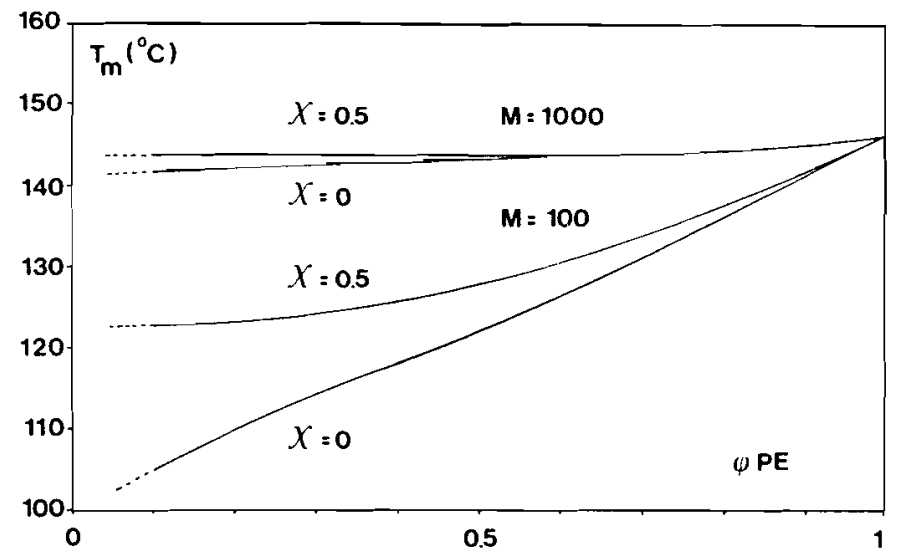

FIG. 11. UHMW-PE liquidus calculated for system UHMW-PE/paraffin $\left(M=100\right.$ and $\left.M=1000 \mathrm{~kg} \mathrm{kmol}^{-1}\right)$; the actual values for the interaction parameter, $\chi$, will be between the two chosen values $\chi=0.5$ and $\chi=0$.

surface growth in terms of a loose entanglement network on the rotor surface. ${ }^{36,37}$

However, as indicated by Smith et al., ${ }^{53}$ UHMW-PE films exhibiting ultra-draw characteristics can be produced by direct polymerization. It is also well known that nascent PE or PP reactor powders, obtained by heterogeneous polymerization, are to some extent disentangled since the chains grow initially independently and form folded or extended-chain type crystals depending on the polymerization conditions. ${ }^{58}$ Therefore a polymerization process could be envisaged producing disentangled UHMW-PE powder directly in the reactor. If so, the 'only' problem left towards a solvent-free route is to process disentangled UHMW-PE powder which is in fact healing of the particles so as to form continuous structures without destroying ultra-drawability. Literature data indicate that crystallization and processing memories persist in polyethylene melts for many hours. ${ }^{59,60}$ In view of the high molecular weight involved $\left(M_{\mathrm{w}}\right.$ typically above $10^{6} \mathrm{~kg} \mathrm{kmol}^{-1}$ ) one expects a 'temperature-time window' for processing (extrusion/spinning) where the initially disentangled status is not completely destroyed with loss of drawability. However in the authors' experience such a ' $T-t$ window' does not exist in practice, for two related reasons:

(a) The rheological properties of UHMW-PE melts, at least in shear and within time-scales (frequency ranges) of practical interest, are independent of the previous sample history. Figure 12 shows the

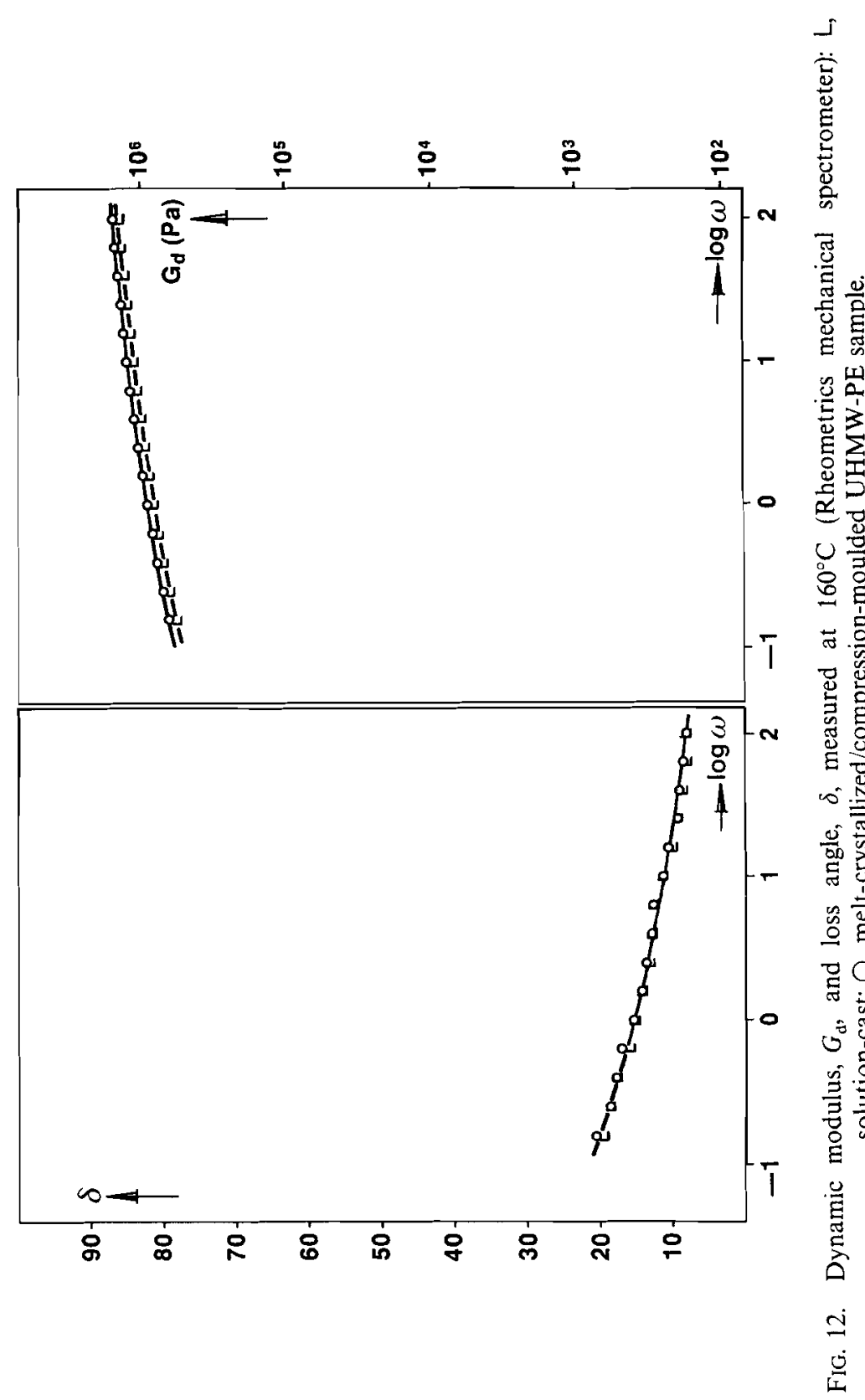




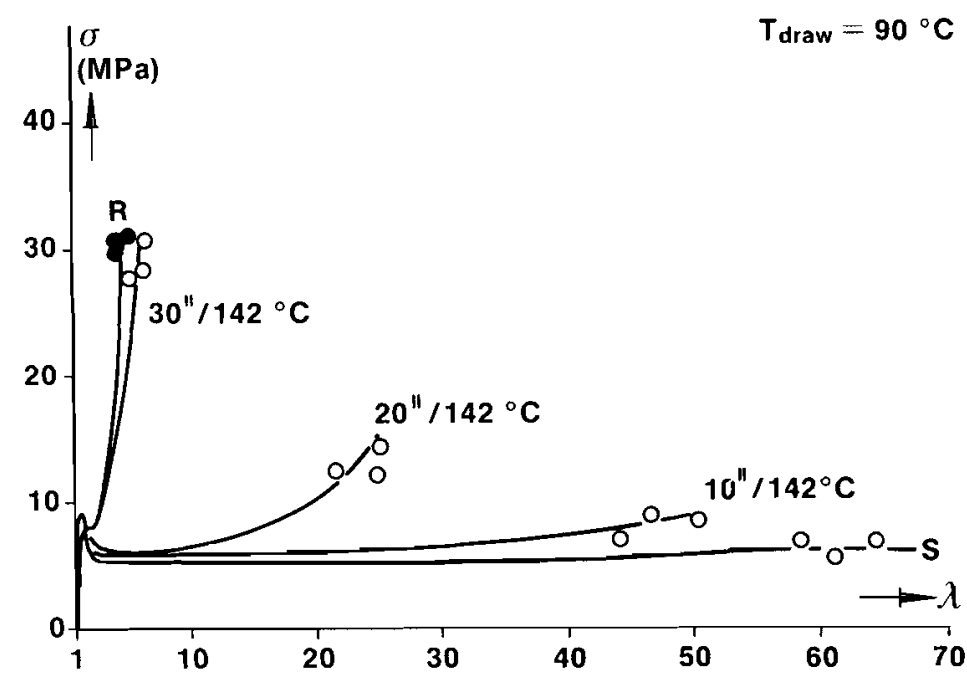

FIG. 13. Effect of melting/recrystallization of solution-crystallized samples (S) (respectively 10,20 and $30 \mathrm{~s}$ at $142^{\circ} \mathrm{C}$ followed by quenching to room temperature) on drawing behaviour $\left(T_{\text {draw }}=90^{\circ} \mathrm{C}\right)$; $\mathrm{R}$ is for melt-crystallized/compressionmoulded sample.

dynamic modulus and the loss angle, measured at $160^{\circ} \mathrm{C}$ (Rheometrics mechanical spectrometer), for two UHMW-PE samples of identical chemical composition (Hostalen Gur 412, $M_{\mathrm{w}}=1.5 \times 10^{6}$ ). No difference within experimental error is observed between the two melts obtained by respectively heating a melt-crystallized sheet and a sintered solution-crystallized film. The solution-crystallized film was obtained by casting from dilute solutions $(<0.5 \%)$ and sintering to remove voids below $T_{\mathrm{m}}$, whilst the melt-crystallized sheet was obtained via compression moulding involving a press-cycle of about $1 \mathrm{~h}$ at $200^{\circ} \mathrm{C}$. The difference between the two films with respect to drawability in the solid state is of the kind shown before in Fig. 8. Upon heating above $T_{\mathrm{m}}$, about $135^{\circ} \mathrm{C}$, the two samples are indistinguishable at least in measurements in shear after $3-5 \mathrm{~min}$, the time needed to reach thermal equilibrium in the equipment. This observation implies that in the actual practice of extrusion (shear) no advantage is gained by starting from disentangled UHMW-PE powder or related structures (gel particles etc.)

(b) If disentangled UHMW-PE, in the form of cast-films or single

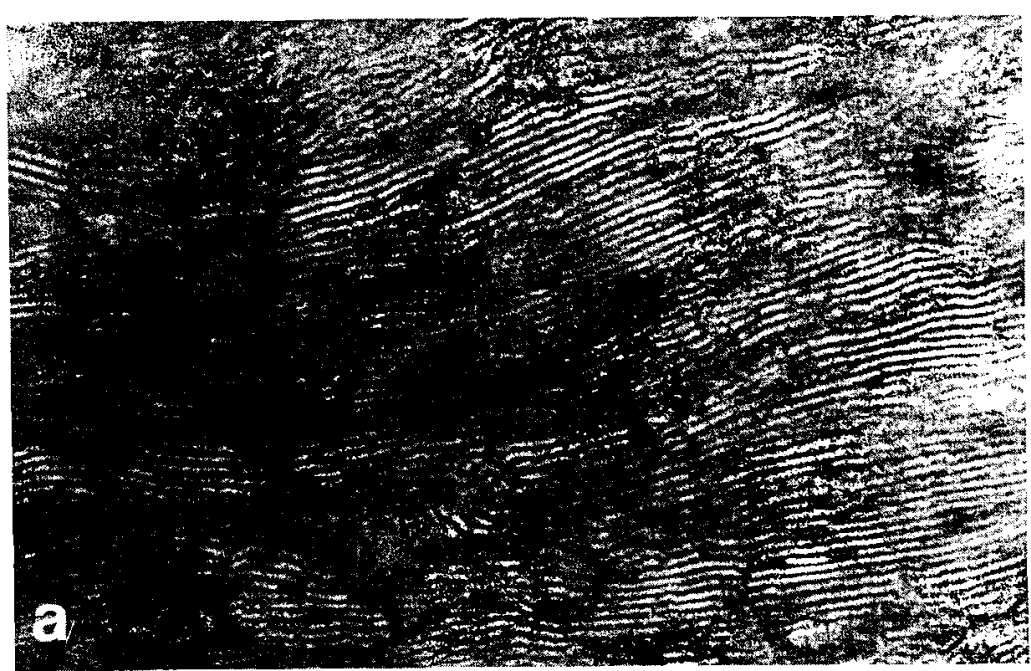

\section{$100 \mathrm{~nm}$}

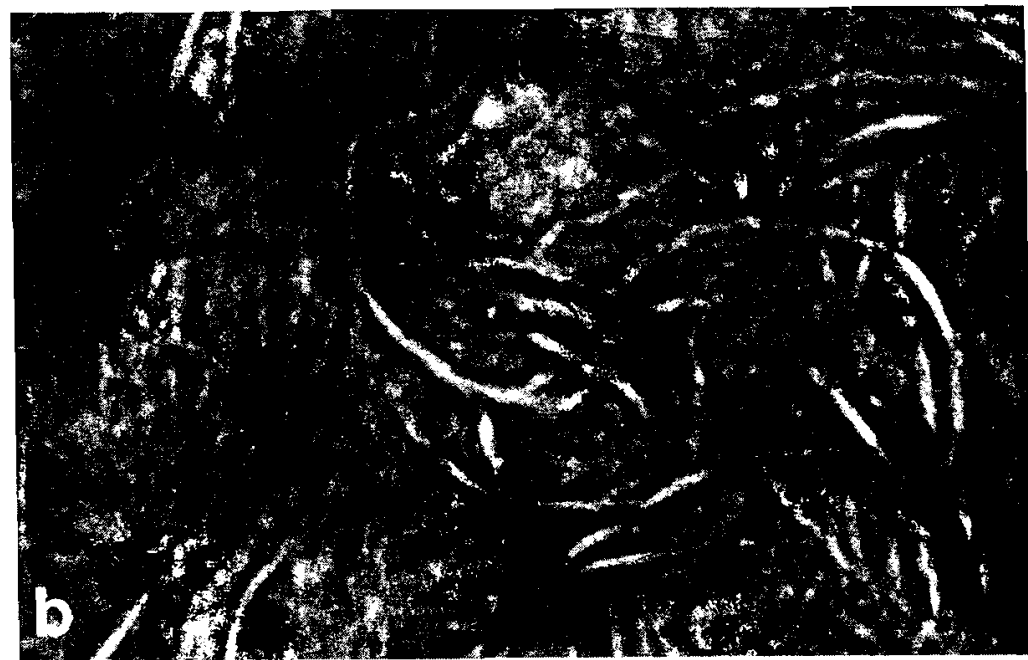

FIG. 14. Morphology of (a) solution-crystallized (cast from $1.5 \%$ solution in decalin) UHMW-PE and (b) recrystallized sample (heated to $150^{\circ} \mathrm{C}$ for $60 \mathrm{~s}$ and quenched). 
crystal mats, is heated above $T_{\mathrm{m}}$ and recrystallized, the ultra-draw characteristics are almost lost immediately. Figure 13 shows the effect of heating a solution-cast film (S) above $T_{m}\left(135^{\circ} \mathrm{C}\right)$, in this case $142^{\circ} \mathrm{C}$, and recrystallizing by quenching to room temperature. Heating for less than $1 \mathrm{~min}$ in the melt is sufficient to cause complete loss of the ultra-draw characteristics, and the sample is indistinguishable in drawing behaviour from a melt-crystallized/ compression-moulded sheet (R). Figure 14 shows the corresponding change in morphology upon heating for about $1 \mathrm{~min}$ above $T_{\mathrm{m}}$ followed by quenching to room temperature.

The short time scale for destroying completely the ultra-draw characteristics upon recrystallization of disentangled UHMW-PE structures reflects a fast molecular reorganization upon melting. The question as to whether re-entangling (reptation ${ }^{29}$ ) or only local, shortrange motions are involved is outside the scope of this review. The main conclusion in practice is that the operating temperature during processing of disentangled UHMW-PE should be kept below the melting temperature, i.e. processing should be restricted to solid-state extrusion. In view of the poor flow properties of solid PE particles it is difficult to envisage a large-scale, solvent-free, spinning/extrusion operation based on disentangled UHMW-PE. However, for the production of large diameter monofilaments or PE tape, solid-state extrusion of disentangled UHMW$\mathrm{PE}$ or related processes such as gel-pressing ${ }^{52}$ seem technologically feasible.

In conclusion it can be said that gel-spinning of UHMW-PE is, at the time of writing, the optimum route for continuous in-line spinning (low viscosity due to presence of solvent)/drawing (optimum morphology, ultra-draw characteristics) in the production of high-strength/highmodulus PE fibres.

\section{SOME PROPERTIES OF HIGH-PERFORMANCE PE FIBRES}

The properties presented in this section were obtained from HP-PE fibres originating from the joint development programme of Toyobo and DSM. One should realize that these properties are of a dynamic nature due to a continuous effort being made towards product and process optimization. A selection has been made to show the potential of HP-PE fibres in some promising applications.

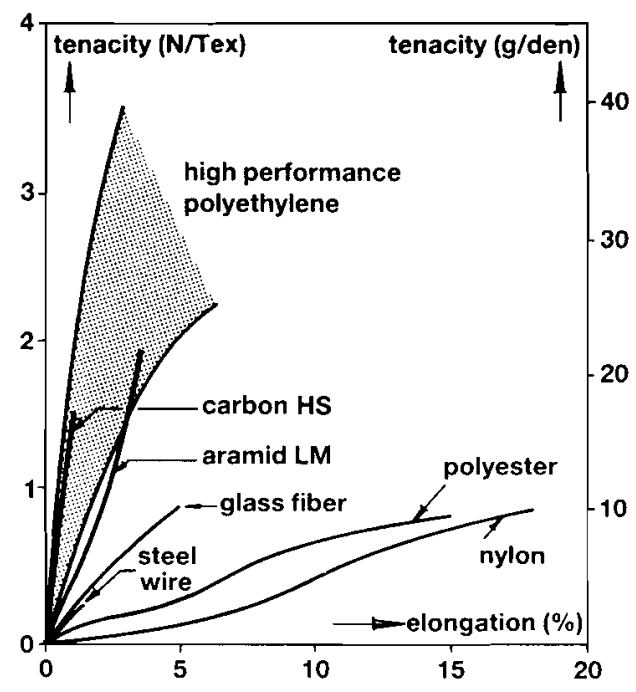

FIG. 15. Stress-strain behaviour of various yarns; $10 \% \mathrm{~min}^{-1}, 23^{\circ} \mathrm{C}$.

\subsection{Stress-Strain Behaviour}

Figure 15 shows tensile strengths ranging from 25 to $40 \mathrm{~g} \mathrm{den}^{-1}$ at a corresponding strain at break of $6-3 \%$ (measured at $23^{\circ} \mathrm{C} /$ crosshead speed $10 \% \mathrm{~min}^{-1}$ ). Young's moduli ranging from 600 to $1800 \mathrm{~g} \mathrm{den}^{-1}$ were recorded, which implies that the specific modulus even of highstrength carbon is surpassed. To avoid any confusion about textile units, a comparison for several materials is shown in Table 4. A comparison as to specific strength/modulus between high-performance PE and some well

TABLE 4

COMPARISON OF TEXTILE UNITS

\begin{tabular}{lcccr}
\hline \multicolumn{1}{c}{ Material } & $\begin{array}{c}\text { Density } \\
\left(\mathrm{g} \mathrm{cm}^{-3}\right)\end{array}$ & $G P a$ & $N$ tex $^{-1}$ & $g$ den $^{-1}$ \\
\hline Nylon & 1.14 & 1.0 & 0.88 & 9.94 \\
Polyester & 1.38 & 1.0 & 0.73 & 8.21 \\
PP & 0.91 & 1.0 & 1.10 & 12.45 \\
Aramids & 1.45 & 1.0 & 0.69 & 7.81 \\
Carbon & 1.77 & 1.0 & 0.56 & 6.40 \\
Glass & 2.5 & 1.0 & 0.40 & 4.53 \\
Steel & 7.8 & 1.0 & 0.13 & 1.45 \\
HP-PE & 0.98 & 1.0 & 1.02 & 11.56 \\
\hline
\end{tabular}




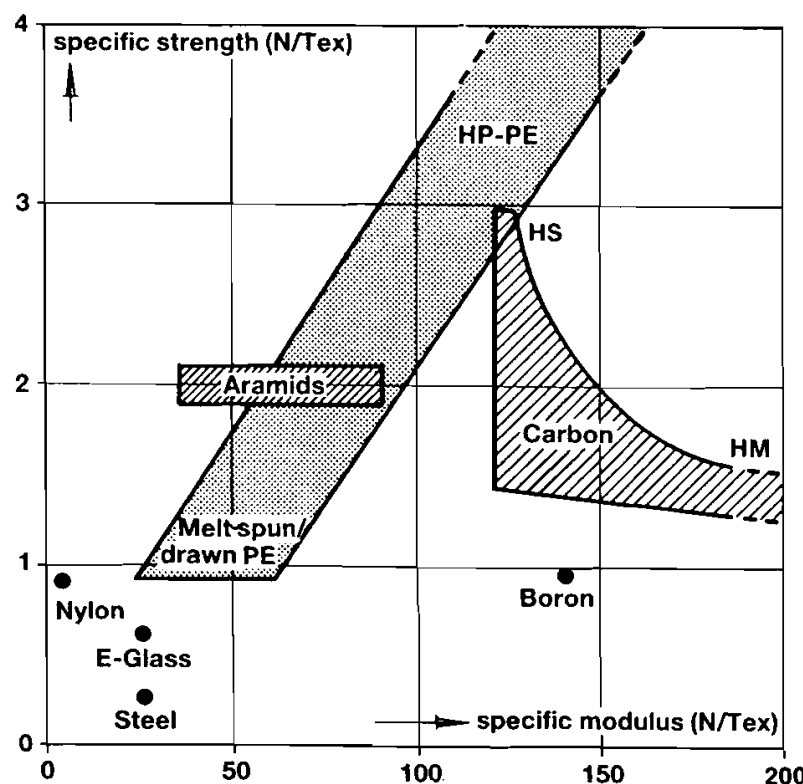

FIG. 16. Specific strength vs. specific modulus.

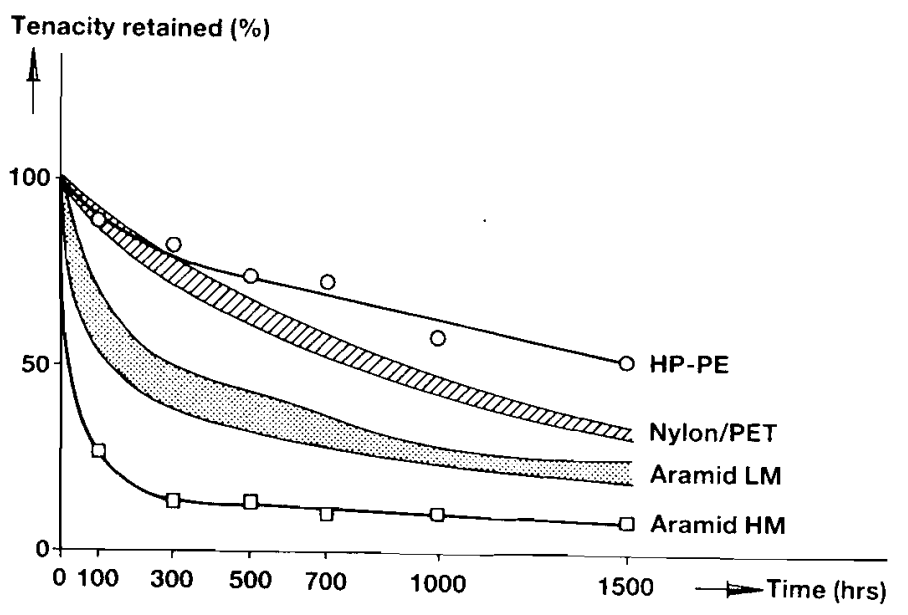

FIG. 17. Resistance to light. known inorganic/organic fibres is shown in Fig. 16. Apart from having the advantage of extreme high strength/stiffness, the textile engineer is able to match the fibre properties to the requirements of the end-user by changing only a few process parameters during the spinning/drawing operation, such as draw ratio and concentration.

\subsection{Light Resistance}

The strength retention after exposure to (artificial) sunlight (JIS L10137.18) in comparison with aramid fibres is given in Fig. 17; it is found to be superior. The exposure time of $300 \mathrm{~h}$ in the Fadometer corresponds roughly to an outdoor exposure time of 6 months. For various marine applications (long exposure times), the advantage is clear.

\subsection{Chemical Resistance}

Due to the simple chemical structure of polyethylene with $\mathrm{C}-\mathrm{C}$ and $\mathrm{C}-\mathrm{H}$ bonds only, no chemical groups are available for attack in harsh environments. The effect of extremely low $\mathrm{pH}\left(\mathrm{H}_{2} \mathrm{SO}_{4}, 95 \%\right)$ and high $\mathrm{pH}$ $(\mathrm{NaOH}, 50 \%)$ on the strength levels in comparison with those of aramid fibres is shown in Fig. 18. The favourable behaviour of HP-PE could be advantageous in filtering applications in the chemical industry.

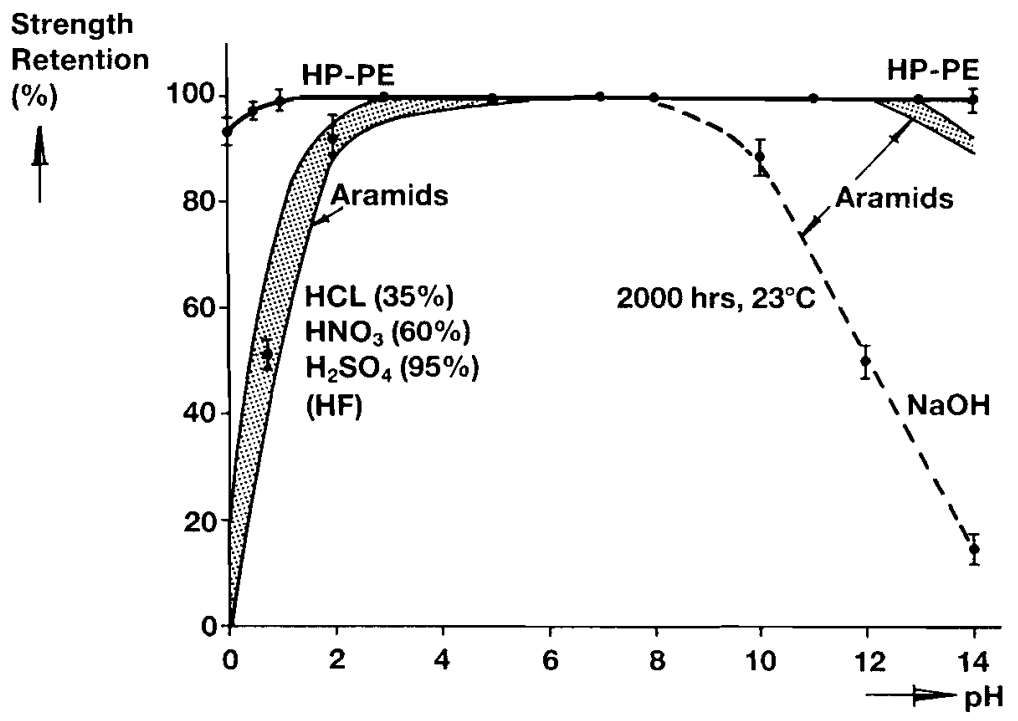

FIG. 18. Chemical resistance; $120 \mathrm{~h}, 23^{\circ} \mathrm{C}$. 


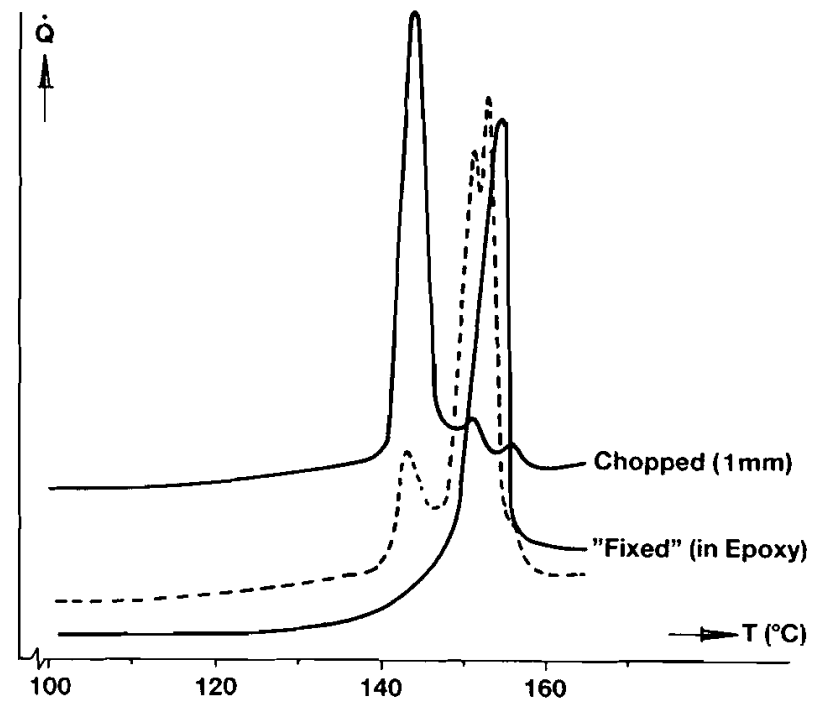

Fig. 19. Melting behaviour of HP-PE. (Reproduced from Reference 29, courtesy of Butterworths.)

\section{Specific Energy Absorption}

(High speed impact, single-ply)

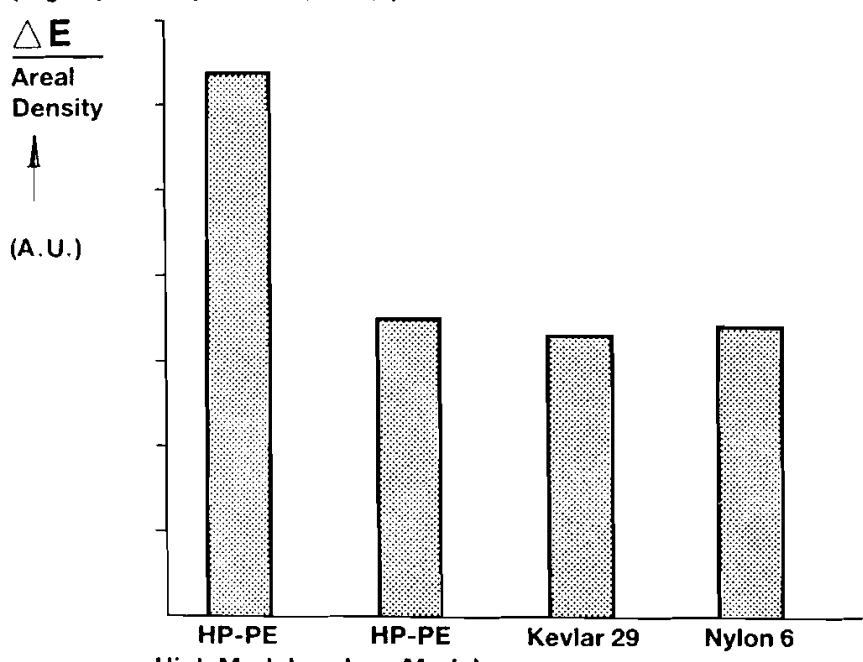

High Modulus Low Modulus

FIG. 20. Specific energy absorption of various fibres/fabrics.

\subsection{Melting Behaviour}

The melting behaviour of HP-PE fibres seems at first sight rather complex (see the dashed line in Fig. 19) due to various constraints imposed on the fibre during the measurement. However, this complex pattern is in fact due to a superposition of two melting modes:

(a) Non-constrained melting (e.g. chopped fibres in silicone oil), showing a single peak at $144^{\circ} \mathrm{C}\left(5^{\circ} \mathrm{Cmin}^{-1}\right)$.

(b) Fully constrained melting (e.g. fibre embedded in an epoxy matrix), showing a single endotherm at about $155^{\circ} \mathrm{C}\left(5^{\circ} \mathrm{C} \mathrm{min}{ }^{-1}\right)$.

The higher melting point of constrained $\mathrm{PE}$ fibres makes it even possible to produce fully HP-PE/PE based composites which offer possibilities in ballistic applications such as 'hard armour'. ${ }^{1,62}$

\subsection{Impact Resistance}

A combination of high modulus, high breaking strength and an elongation at break of 3-6\% leads to a high (calculated) value of the work to break of the fibre (see Table 5). A comparison of two types of HP-PE, Kevlar-29 and nylon-6, is given in Fig. 20, with the absorbed energy measured in high-speed impact testing. It is in particular this superior impact property that makes HP-PE a good candidate for several protective textile and composite applications. ${ }^{62}$

\subsection{Abrasion/Flex/Bending Properties}

Due to the low friction coefficient of polyethylene (UHMW-PE is famous for this unique property as an engineering plastic), the abrasion resistance

TABLE 5

MODULUS AND WORK-TO-BREAK FOR HIGH-PERFORMANCE FIBRES

\begin{tabular}{lcc}
\hline Material & $\begin{array}{c}\text { Young's modulus } \\
\left(N \text { tex }^{-1}\right)\end{array}$ & $\begin{array}{c}\text { Work to break } \\
\left(\text { N }^{a} \text { tex }^{-1}\right) \times 10^{3}\end{array}$ \\
\hline Carbon HS & 125 & $1-2$ \\
Aramid HM & 80 & $2 \cdot 5-3 \cdot 0$ \\
Aramid LM & 40 & $3 \cdot 5-4 \cdot 0$ \\
Polyethylene & 50 & $11-13$ \\
Polyethylene & 80 & $8-10$ \\
Polyethylene & 100 & $8-9$ \\
Polyethylene & 130 & $\sim 8$
\end{tabular}

${ }^{a}$ Calculated by integration of the stress-strain curve. 


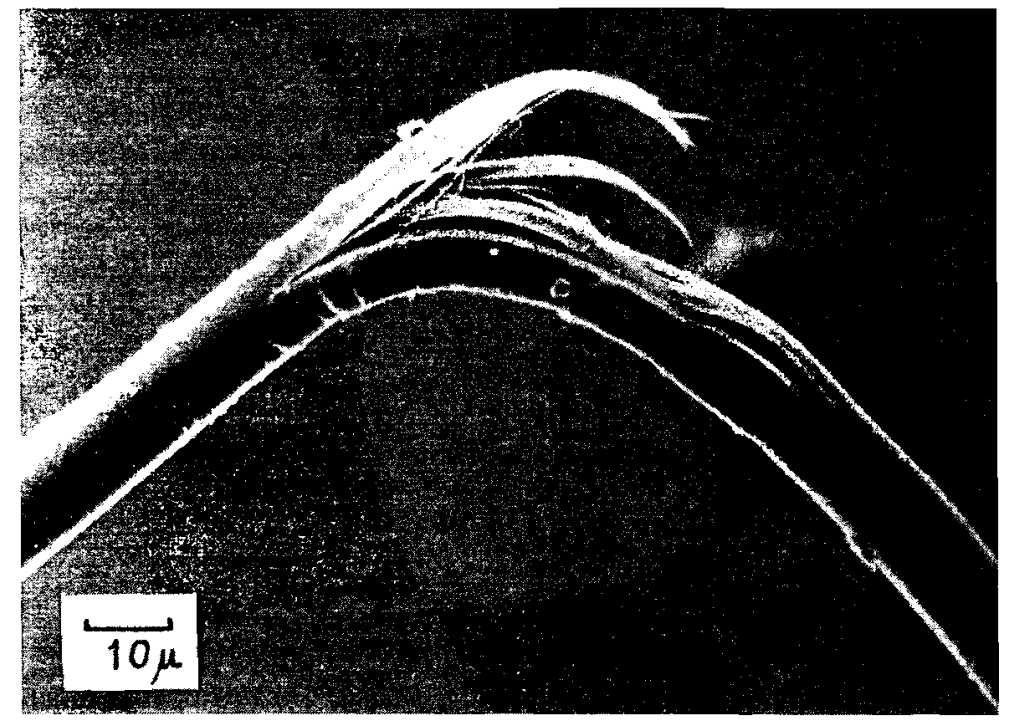

(a)

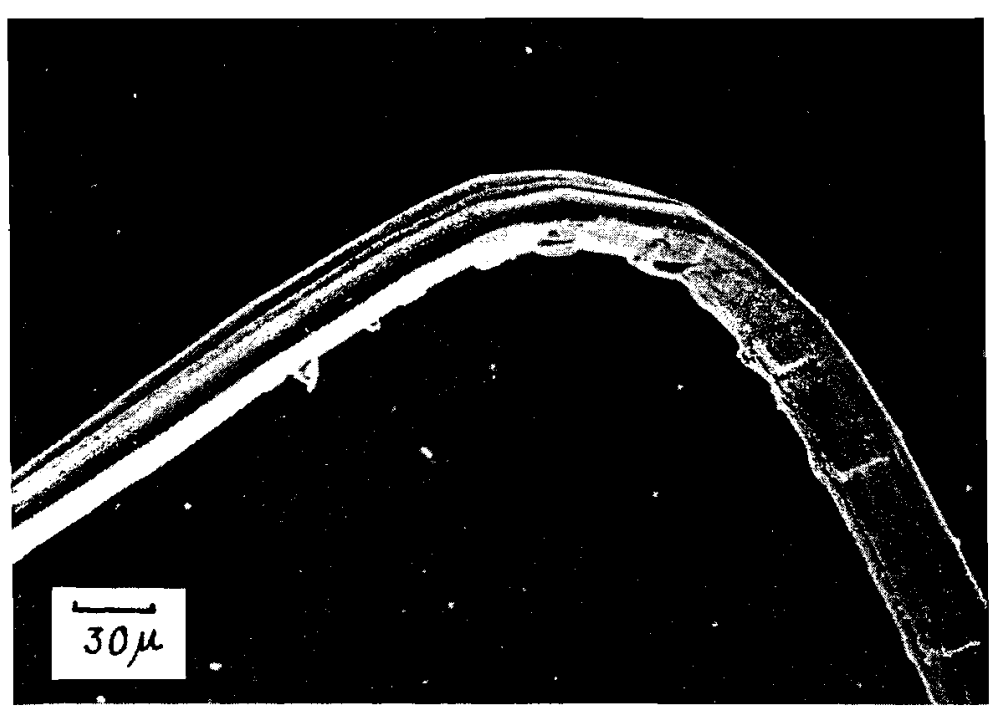

(b)

FIG. 21. Behaviour of fibres in loop-strength tests. (a) Kevlar 49; (b) HP-PE.

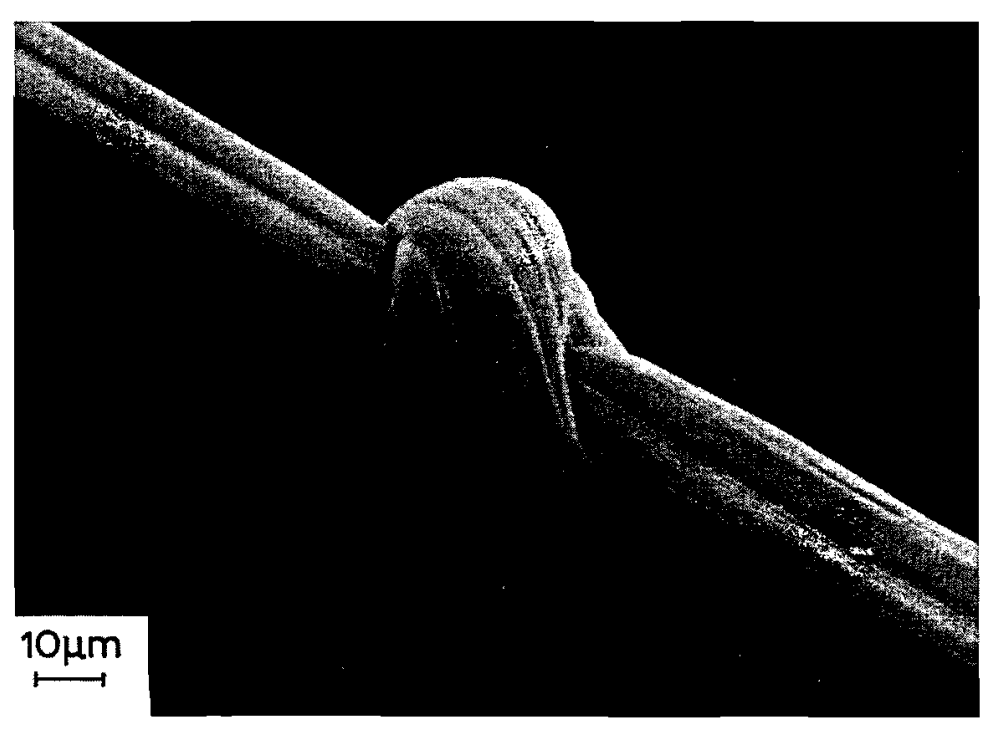

(a)

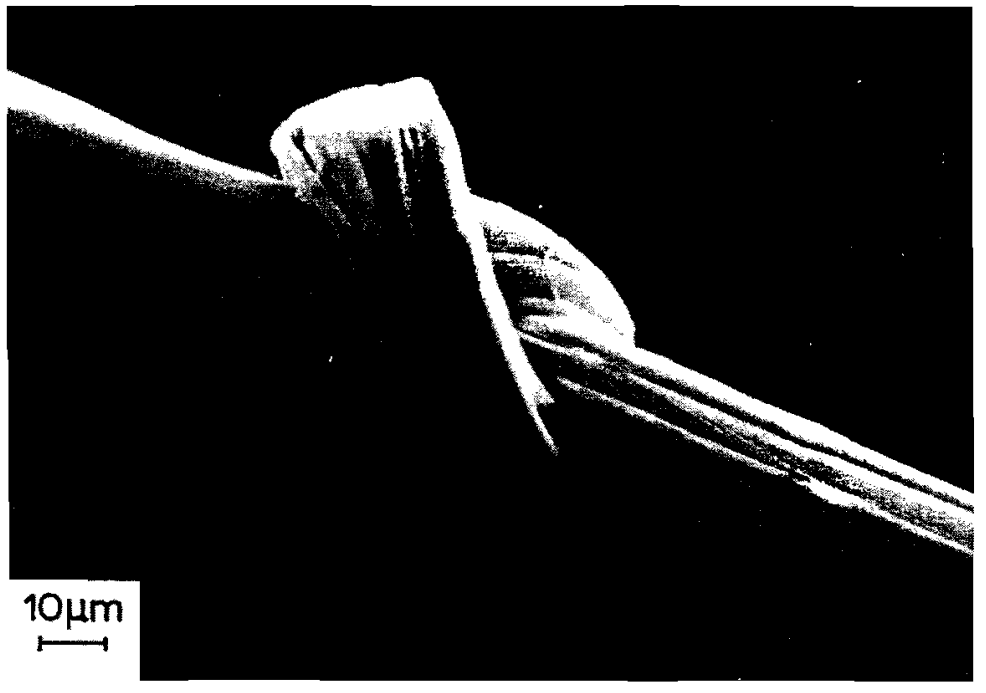

(b)

FIG. 22. SEM micrographs revealing knots in monofilaments of (a) HP-PE and (b) aramids. 
TABLE 6

YARN PROPERTIES

\begin{tabular}{lccccc}
\hline & HP-PE & Kevlar 29 & Kevlar 49 & $\begin{array}{c}\text { Carbon } \\
H T\end{array}$ & $\begin{array}{c}\text { Carbon } \\
H M\end{array}$ \\
\hline $\begin{array}{c}\text { Abrasion resistance } \\
\text { (cycles to break) }\end{array}$ & $>110 \times 10^{3}$ & $9.5 \times 10^{3}$ & $5 \cdot 7 \times 10^{3}$ & 20 & 120 \\
$\begin{array}{c}\text { Flex life } \\
\text { (cycles to break) }\end{array}$ & $7240 \times 10^{3}$ & $37 \times 10^{3}$ & $43 \times 10^{3}$ & 5 & 2 \\
$\begin{array}{c}\text { Knot strength } \\
\left(\mathrm{g} \mathrm{den}^{-1}\right) \\
\text { Loop strength } \\
\left(\mathrm{g} \mathrm{den}^{-1}\right)\end{array}$ & $10-15$ & $6-7$ & $6-7$ & 0 & 0 \\
\hline
\end{tabular}

measured according to JIS L1095-7.10.2, is absolutely superior to that of other high-performance fibres, as shown in Table 6. More generally speaking, the properties of the fibre during single or repeated bending show the enormous potential of HP-PE in the market for ropes and lightweight fabrics. Both knot strength and loop strength are the highest found in any man-made material related to the intrinsic flexible nature of polyethylene macromolecules. This is also demonstrated in Fig. 21, showing the aramid and HP-PE fibres after being tested for loop strength. Before rupture the tested monofilaments were examined in the scanning microscope, revealing kinking in the case of PE and splitting for the aramids. The favourable bending behaviour of PE is shown once more in Fig. 22, revealing knotted monofilaments.

\subsection{Long-term Properties}

Creep of HP-PE fibres is dependent on a large variety of factors, such as $E$ modulus, molecular weight and molecular weight distribution, spinning concentration etc., and is subject to change in the future due to improved control of process and product quality and optimization with respect to the aforementioned parameters. Therefore no definite creep curves for HP-PE can be given. However, it remains an interesting question whether there will be a consistent difference between HP-PE fibres produced from low-volatility solvents and fibres from paraffinic oil, in particular paraffin waxes. Figure 23 shows some comparative data, in particular for creep at $80^{\circ} \mathrm{C}$, i.e. above the melting point of paraffinic wax. These data suggest that residual solvent could promote creep, which is understandable in terms of lubrication of individual microfibrils.

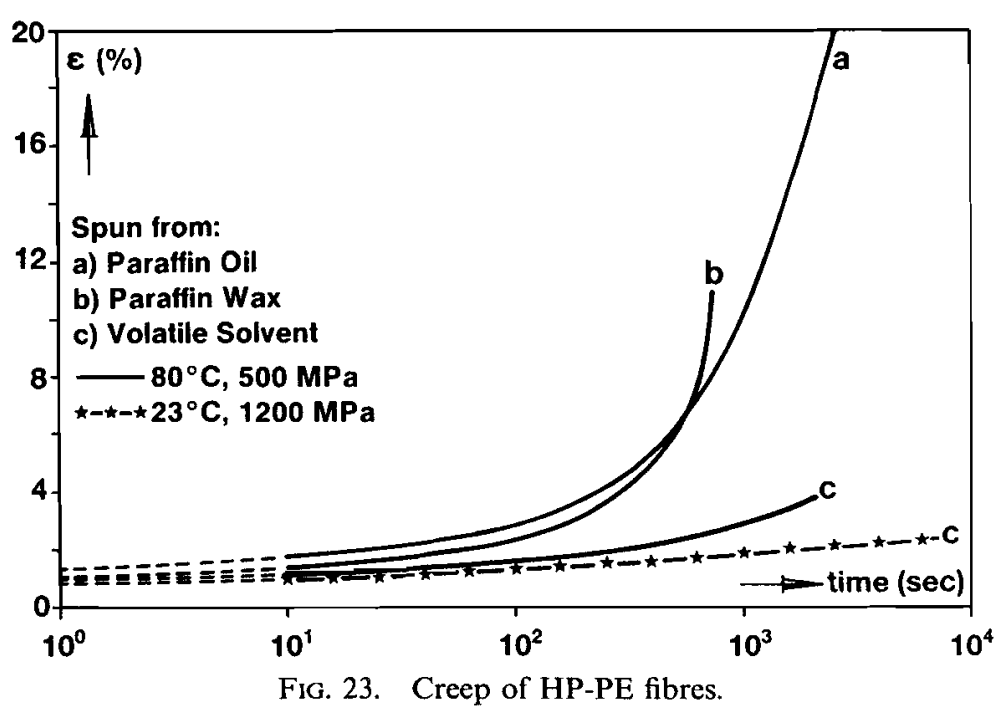

\section{OTHER FLEXIBLE POLYMERS}

Since the invention of the gel-spinning process for polyolefins, a lot of effort has been devoted towards the utilization of this concept for other flexible polymers.

High molecular weight polypropylene was investigated in detail by Peguy and Manley; ${ }^{63}$ by ultra-drawing of dried gels oriented PP structures were obtained possessing moduli of up to $36 \mathrm{GPa}$ and corresponding tenacities of about $1 \mathrm{GPa}$. Their experimentally obtained moduli are close to the theoretical limits (compare with Table 1), but of course rather low in comparison with the values for HP-PE due to the helical conformation of isotactic PP in the crystalline state.

An interesting candidate is polyvinylalcohol (PVAL). Despite its atactic character, PVAL is crystallizable, possesses the all-trans conformation in the crystalline state, and the crystal structure is very similar to that of polyethylene. The advantage over PE is its higher melting point, $>200^{\circ} \mathrm{C}$. Allied researchers copied their 'xero-gel' process ${ }^{44}$ for the production of PVAL fibres. ${ }^{64}$ High molecular weight PVAL was obtained by lowtemperature photo-initiated polymerization of vinyl acetate followed by methanolysis. Molecular weights above $5 \times 10^{5} \mathrm{~kg} \mathrm{kmol}^{-1}\left(M_{\mathrm{w}}\right)$ and up to several millions were used in their spinning experiments. Tenacities of the fibres of up to about $20 \mathrm{~g} \mathrm{den}^{-1}(2.3 \mathrm{GPa})$ and corresponding tensile 
moduli of about $600 \mathrm{~g} \mathrm{den}^{-1}(70 \mathrm{GPa})$ were reported. The use of high molecular weight was claimed to be essential. ${ }^{64,65}$ However, as reported by Toray, ${ }^{66}$ similar values for tenacity and modulus can be obtained using rather standard molecular weight PVAL $\left(M_{\mathrm{w}}\right.$ in the range 1.3$1.8 \times \mathrm{kmol}^{-1}$ ). This shows immediately the difficulty in relating in particular the tenacity to the chain length. Stronger interaction between chains makes the drawing process, i.e. chain-extension, more difficult but renders a higher value for tenacity and in particular a better resistance to creep for lower molecular weights. In this respect the polyamides are attractive due to the specific hydrogen bonding in the crystalline state, but no impressive values have been obtained via solution-spinning as yet. ${ }^{67}$ High molecular weight nylon- $6\left(M_{\mathrm{w}} 3.5 \times 10^{6}\right)$ was spun from solution and drawn. Tenacities up to about $1 \mathrm{GPa}$ and corresponding moduli of $19 \mathrm{GPa}$ were obtained, to be compared with tenacity $0.8 \mathrm{GPa}$ and modulus $6 \mathrm{GPa}$ for technical melt-spun yarns.

A final example of the utilization of the gel-spinning process for flexible polymers is poly(acrylonitrile). Technical PAN yarns based on standard molecular weights $\left(M_{\mathrm{w}} 5-10 \times 10^{4} \mathrm{~kg} \mathrm{kmol}^{-1}\right)$ possess tensile strengths of $0.8 \mathrm{GPa}$ and moduli of about $15 \mathrm{GPa}{ }^{68} \mathrm{High}$ molecular weight PAN $\left(M_{\mathrm{w}}\right.$ about $10^{6} \mathrm{~kg} \mathrm{kmol}^{-1}$ ) was employed ${ }^{69}$ but no significant increase in properties was obtained, at least with respect to tenacity, viz. $0.8 \mathrm{GPa}$ and corresponding moduli of about $27 \mathrm{GPa}$. A major improvement in tenacity was reported ${ }^{70}$ by spinning of high molecular weight PAN from solutions which contain bivalent metal ions, for example $\mathrm{Zn}^{2+}$. The presence of bivalent ions promotes the formation of homogeneous gel-filaments and prevents to some extent the $\mathrm{L}-\mathrm{L}$ phase separation which usually occurs during coagulation in conventional wet-spinning processes. The combination of high molecular weight and specific metal ions results in tenacity values greater than $1.5 \mathrm{GPa} .{ }^{70}$ Similar values have been reported by Japan Exlan. ${ }^{71}$ An intriguing question which remains is whether these HS-PAN fibres could lead to better carbon fibres with respect to tenacity and improved toughness. In other words, will a higher tenacity, due to improved chain orientation and higher molecular weight, of the precursor be reflected in the properties of the carbon fibres after oxidation/carbonization? ${ }^{72}$

\section{CONCLUSIONS}

The properties of the various fibres based on flexible macromolecules, as presented in this review, are of a dynamic nature; due to the continuous efforts made at process and product optimization, improvements are foreseen.

In the case of HP-PE fibres one could classify three application areas:

New, as yet unexplored markets related to the unique properties of HP-PE.

Combination of HP-PE with other high-performance-fibres in hybrid structures, both composites and textiles.

Substitution of currently used high-performance-fibres, such as aramids, carbon and glass, mainly depending on price/performance criteria.

In general, apart from gel-spinning (solution-spinning of high molecular weight flexible polymers followed by ultra-drawing), increased activity is foreseen towards the utilization of 'gel technology' for the production of two- and three-dimensional strong and stiff structures based on flexible polymers.

\section{REFERENCES}

1. Carothers, W. and Hill, J. W. (1932). J. Am. Chem. Soc., 54, 1586.

2. W-FANG Hwang (1985). Proc. Symp. Formation, structures and properties of high-modulus and high-tenacity fibres, Kyoto, p. 23.

3. W-Fang Hwang (1985). Proc. Int. Symp. Fibre Sci. Technol. (ISF), Hakone p. 39.

4. Smith, P Matheson, R. R. and Irvine, P. A. (1984). Polymer Commun., 25, 294.

5. Tanner, D., Fitzgerald, J. A., Knoff, W. F. and Pigliacampi, J. J. (1985) Proc. ISF, Hakone, p. 31.

6. Perepelkin, K. E. (1972). Angew. Makromol. Chem., 22, 181.

7. Sakurada, I. and Kaul, K. (1970). J. Polym. Sci. C, 31, 57.

8. Storks, K. H. (1938). J. Am. Chem. Soc., 60, 1753.

9. JACCODINE, R. (1955). Nature, 176, 305. Keller, A. (1957). Phil. Mag., 2, 1171. Fischer, E. W. (1957). Z. Naturforsch., 12a, 753. Till, P. H. (1957). J. Polym. Sci., 24, 301

10. MARK H. F (1971) In: Polymer science and materials (Ed. H. F. Mark and A V. Tobolsky), Wiley-Interscience, New York, p. 236.

11. Boudreaux, D. S. (1973). J. Polym. Sci. Phys. Ed., 11, 1285.

12. Peterlin, A. (1979). In: Ultra-high modulus polymers (Eds. A. Ciferri and I. M Ward), Applied Science Publishers, London, p. 279.

13. JURGENLEIT, W. (1962). US Patent 3,048,465 (appl. Germany, June 16, 1956).

14. Sato, H. and Hirai, N. (1962). Jap. Sho 37-9765.

15. ZWICK, M. (1965). NL 6501248

16. Blades, H. and White, J. R. (1963). US Patent 3,081,519.

17. Mitsuhashi, S. (1963). Bull. Text. Res. Inst., 66, 1. 
18. Petrie, C. J. S. (1979). Elongation flows, Pitman, London, Ch. 4.

19. MACKLey, M. R. and SAPSFORD, G. S. (1982). In: Developments in oriented polymers (Ed. I. M. Ward), Applied Science Publishers, London.

20. Mackley, M. R. and Keller, A. (1975). Phil. Trans. Roy. Soc., A278, 29.

21. Keller, A. and Odell, J. A. (1985). Colloid. Polym. Sci., 263, 181.

22. Statton, W. O. (1967). J. Appl. Phys., 38, 4149.

23. Ishikawa, K. MiYasaka, K. and Maeda, M. (1969). J. Polym. Sci. A-2, 7, 2029.

24. Maeda, M., Miyasaka, K. and Ishikawa, K. (1970). J. Polym. Sci. A-2, 8, 355.

25. Barham, P. J. and Keller, A. (1976). J. Mater. Sci., 11, 27.

26. ANDREWS, J. M. and WARD, I. M. (1970). J. Mater. Sci., 5, 411.

27. Capaccio, G. Gibson, A. G. and WARD, I. M. (1979). In: Ultra-high modulus polymers (Eds. A. Ciferri and I. M. Ward), Applied Science Publishers, London, Ch. 1.

28. Stamm, M., Fischer, E. W., Dettenmaier, M. and Convert, P. (1979). Faraday Discuss. Roy. Soc. Chem., 68, 263.

29. Lemstra, P. J. and Kirschbaum, R. (1985). Polymer, 26, 1372.

30. Sadler, D. M. and Odell, J. A. (1980). Polymer, 21, 479.

31. (1984). Eur. Chem. News, 43, 22.

32. Gibson, A. G., Ward, I. M., Cole, B. N. and Parsons, B. (1974). J. Mater. Sci., 9, 1193

33. Perkins, W. G. Capiati, N. J. and Porter, R. S. (1976). Polym. Eng. Sci., 16, 3.

34. Nat. Res. Dev. Corp., European Patent Appl. 38798.

35. Pennings, A. J., van den Mark, J. M. A. A. and Bools, H. C. (1970). Colloid Polym. Sci., 236, 99.

36. Keller, A. And Barham, P. J. (1981). Plastics Rubber Int., 6, 19

37. Barham, P. J. and Keller, A. (1985). J. Mater. Sci., 20, 2281.

38. Pennings, A. J. (1977). J. Polym. Sci. Polym. Symp., 59, 55.

39. Zwijnenburg, A. and Pennings, A. J. (1975). Colloid Polym. Sci., 253, 452.

40. DSM/Stamicarbon, NL 7605370 (1976)/US Patent 4,137,394.

41. ZwiJnENBURG, A. (1978). Ph.D. Thesis, University of Groningen, Netherlands

42. DSM/STAMICARBON, NL 7900990 (1979); 7904990 (1979)/US Patent 4,344,908; $4,422,993 ; 4,436,689$.

43. PrevorseK, D. C. (1982). Polymer liquid crystals, Academic Press, p. 357

44. Allied Fibres, Eur. Patent 64167 (1982)

45. Kalb, B. and Pennings, A. J. (1980). Polymer, 21, 3.

46. Wilding, M. A. and Ward, I. M. (1978). Polymer, 19, 969.

47. Mitsui, Eur. Patent 115.192 (1984).

48. Kanamoto, T., Tsuruta, A., Tanaka, K., Takeda, M. and Porter, R. S. (1983). Polymer. J., 15, 327

49. MiYASAKA, K, in Reference 3, p. 27.

50. Matsuo, M. and Sawatari, V., in Reference 3, p. 152.

51. Kanamoto, T., Tanaka, K., Takeda, M. and Porter, R. S., in Reference 3, p. 155.

52. Точово, Eur. Patent $84113352.3 / 141418$

53. Smith, P., Chanzy, H. D. and Rotzinger, B. P. (1985). Polym. Commun., 26, 257.

54. Smith, P., Lemstra, P. J. and Booy, H. C. (1981). J. Polym. Sci. Polym. Phys. Ed., 19,877.
55. LemSTra, P. J. and SMITH, P. (1980). Brit. Polym. J., 12, 212.

56. Furuhata, K., Yokokawa, T. and Miyasaka, K. (1984). J. Polym. Sci. Polym. Phys, Ed., 22, 133.

57. FLORY, P. J. (1953). Principles of polymer chemistry, Cornell University Press, Ch. XIII.

58. Boor, J. (1979). Ziegler-Natta catalysts and polymerizations, Academic Press, New York, Ch. IV.

59. Folland, R. and Charlesby, A. (1979). Eur. Polym. J., 15, 953.

60. SChreiber, H. P. (1983). Polym. Eng. Sci., 23, 422.

61. Allied CORP, Eur. Patent 110.021 (1984).

62. Adams, D. F., Zimmerman, R. S. and Won Chang, H. (1985). SAMPE J., 44

63. Peguy, A. and Manley, R. St J. (1984). Polym. Commun., 25, 39.

64. Allied Fibres, Eur. Patent. 105.169 (1984)

65. Prevorsek, D. C., in Reference 2, p. 20.

66. Toray Industries, Eur. Patent 146.084 (1985).

67. Gogolewski, S. and Pennings, A. J. (1984). Polymer, 26, 1394.

68. HoECHST, Technical Bulletin 198b (Dolan-10).

69. Allied Fibres, Eur. Patent 144.793 (1985).

70. DSM/STamiCARbon, Eur. Patent 114.983 (1984).

71. JAPAN ExLAN Co., US Patent 4,535,027 (1985)

72. SANTAPPA, M. (1982). J. Indian Chem., 59, 321 .

73. Lemstra, P. J., van Aerle, N. A. M. J. and Bastiaansen, C. W. N. (1987). Polymer J., 19, 85.

Note added on proof

Since the time of writing this chapter considerable progress has been made in the area of UHMW-PE gel-spinning. For further reading see for example ref. 73 . 